University of Tennessee Health Science Center

UTHSC Digital Commons

\title{
$5-2016$
}

\section{Super-Utilization: The New Perfect Storm of Health Reform}

Jill Diane Nault

University of Tennessee Health Science Center

Follow this and additional works at: https://dc.uthsc.edu/dissertations

Part of the Health and Medical Administration Commons, Health Services Administration Commons, and the Health Services Research Commons

\section{Recommended Citation}

Nault, Jill Diane (http://orcid.org/0000-0003-0497-0736), "Super-Utilization: The New Perfect Storm of Health Reform" (2016). Theses and Dissertations (ETD). Paper 390. http://dx.doi.org/10.21007/ etd.cghs.2016.0403.

This Dissertation is brought to you for free and open access by the College of Graduate Health Sciences at UTHSC Digital Commons. It has been accepted for inclusion in Theses and Dissertations (ETD) by an authorized administrator of UTHSC Digital Commons. For more information, please contact jwelch30@uthsc.edu. 


\title{
Super-Utilization: The New Perfect Storm of Health Reform
}

\begin{abstract}
This three-essay dissertation was focused on geographic variation of super-utilization, or the disproportionately high healthcare utilization and costs attributed to a small sub-set of the inpatient population. For purposes of this research, super-utilization was operationalized as high repeat utilization (HRU) and referred to inpatient utilization and inpatient readmission expenditures attributed to beneficiaries with four or more 30-day readmissions per year. The overall purpose of the research was to identify geographic areas at increased risk for HRU. These areas corresponded to where beneficiaries live and were aligned with the geographically-bound healthcare delivery systems. Each essay employed an observational study design using 100\% Medicare Part A claims data on beneficiaries ages 65 and older residing in Tennessee hospital referral regions during the 2012 study period. The first essay focused on the impact of super-utilization on population-based rates of readmission across healthcare delivery systems. Specific aims of the first essay were: 1) to assess geographic variation in a population-based overall rate of readmissions across local healthcare delivery systems by conducting one sample means testing use the $Z$ statistic to determine whether rates were lower, higher, or no different from the state average; 2 ) to contrast the number of beneficiaries, readmission events, and inpatient readmission expenditures attributed to beneficiaries with one compared to four or more readmissions per year between local delivery systems in the 10th and 90th percentiles of readmission rates using descriptive statistics; and 3) to assess the effect of the number of readmissions by beneficiaries with one, two, three, and four or more readmissions per year on overall readmission rates using a quasi-experimental approach to linear regression. The second essay focused on identifying clusters of super-utilization across healthcare delivery systems. Specific aims of the second essay were: 1) to detect statistically significant clusters of concentrated readmission events attributed specifically to HRU by using the SatScanTM method for spatial scan statistics; 2 ) to explore overlap of identified clusters with populationbased rates of readmission using chloropleth mapping to visually depict the relationship; and 3) to assess differences in the geographic distribution of readmission events attributed to HRU between urban and rural locations within cross-border areas using the Mann-Whitney $U$ test to determine statistical significance. The third essay focused on predicting risk of super-utilization across healthcare delivery systems using community demographic variables. Specific aims of the third essay were: 1 ) to assess the effect of rurality, income, and race on the presence of HRU using a logistic regression model; 2) to determine whether differences in model effects existed among regional healthcare delivery systems by including region as a class variable within the model; and 3) to evaluate whether differences in model effects existed at various concentrations of low-income households by performing decomposition analysis using contrasts based on percentiles of the distribution of low-income households. Findings on the whole suggest that local healthcare delivery systems with high population-based rates of overall readmissions are also more likely to have underlying issues related to super-utilization. In fact, half of all inpatient readmission expenditures attributed to super-utilization across the study area were concentrated in local healthcare delivery systems in the 90th percentile of readmission rates. Unsurprisingly, clusters of super-utilization overlapped these local healthcare delivery systems with high rates. However, clusters of super-utilization were identified in all regions including some local healthcare delivery systems with rates no different or lower than the statewide per capita rate of readmissions. Furthermore, the highest risk of super-utilization occurred in areas with the highest concentration of lowincome households, regardless of rural-urban designation, household race, or region.
\end{abstract}

\section{Document Type}

Dissertation 


\section{Degree Name}

Doctor of Philosophy (PhD)

\section{Program}

Health Outcomes and Policy Research

\section{Research Advisor}

James E. Bailey, M.D.

\section{Keywords}

geographic variation, inpatient hospital expenditures, Medicare, population health, readmissions, superutilizer

\section{Subject Categories}

Health and Medical Administration | Health Services Administration | Health Services Research | Medicine and Health Sciences | Public Health 


\title{
Super-Utilization: The New Perfect Storm of Health Reform
}

\author{
A Dissertation \\ Presented for \\ The Graduate Studies Council \\ The University of Tennessee \\ Health Science Center
}

In Partial Fulfillment

Of the Requirements for the Degree

Doctor of Philosophy

From The University of Tennessee

By

Jill Diane Nault

May 2016 
Copyright (C) 2016 by Jill Diane Nault. All rights reserved. 


\section{DEDICATION}

This dissertation is dedicated to the patients who have shared their experiences of managing health and interacting with the healthcare system from a complex and multifaceted perspective of challenges and opportunities. These stories have provided the inspiration to not only complete this work but also to dedicate future efforts to make care more patient-centered. I have been truly humbled and blessed to learn from your knowledge. 


\section{ACKNOWLEDGEMENTS}

I am extremely thankful to my husband Gary who has been my rock of stability, support, patience, and unconditional love through the trials and tribulations that came with completion of this dissertation. I am also very blessed to have two beautiful children who can always make me smile and have kept me connected to the important things in life. I also want to thank my parents, family members, and friends for ongoing encouragement and support.

I would also like to acknowledge the members of my committee for their highquality mentorship and undying support throughout the research process. Specifically, I'd like to thank Jim Bailey for providing the opportunities that have shaped and influenced this research as well as supporting the pursuit of research ideas that were meaningful to me. I'd like to thank Dawn FitzGerald for providing the vision for this research, directing it toward important practical questions, and for always believing in me. I'd like to thank Ginna Betts for challenging me to think about the policy implications of findings and what the research will mean to whom. I'd like to thank Carolyn Graff for bringing my attention to important details in writing as well as her enthusiasm and support through changes encountered as the research evolved. I'd like to thank Erik Carlton for his insight and support for continued research efforts and next steps. I'd like to thank Cyril Chang for his monumental assistance with organizing content, challenging research questions and how they could be answered, as well as developing coherent research aims. I'd like to thank George Relyea for being a bridge between understanding the research questions and helping me to answer them in a powerful way, for not only sharing his deep knowledge of statistical theory but also his ability to make interpretations meaningful for a general audience, and for his overall dedication and willingness to help students. I'd like to thank Esra Ozdenerol for sharing her deep knowledge and experience with spatial analysis, for introducing new techniques required to answer questions, and for making sure needed resources were available. I'd also like to thank Dean Thomason for his enormous administrative support.

Finally, I'd like to acknowledge support from the staff at Qsource for preliminary work to this dissertation. Data used in this dissertation was obtained under contract with Qsource as the Medicare Quality Improvement Organization for Tennessee. 


\begin{abstract}
This three-essay dissertation was focused on geographic variation of superutilization, or the disproportionately high healthcare utilization and costs attributed to a small sub-set of the inpatient population. For purposes of this research, super-utilization was operationalized as high repeat utilization (HRU) and referred to inpatient utilization and inpatient readmission expenditures attributed to beneficiaries with four or more 30day readmissions per year. The overall purpose of the research was to identify geographic areas at increased risk for HRU. These areas corresponded to where beneficiaries live and were aligned with the geographically-bound healthcare delivery systems. Each essay employed an observational study design using 100\% Medicare Part A claims data on beneficiaries ages 65 and older residing in Tennessee hospital referral regions during the 2012 study period.

The first essay focused on the impact of super-utilization on population-based rates of readmission across healthcare delivery systems. Specific aims of the first essay were: 1) to assess geographic variation in a population-based overall rate of readmissions across local healthcare delivery systems by conducting one sample means testing use the $\mathrm{Z}$ statistic to determine whether rates were lower, higher, or no different from the state average; 2) to contrast the number of beneficiaries, readmission events, and inpatient readmission expenditures attributed to beneficiaries with one compared to four or more readmissions per year between local delivery systems in the 10th and 90th percentiles of readmission rates using descriptive statistics; and 3) to assess the effect of the number of readmissions by beneficiaries with one, two, three, and four or more readmissions per year on overall readmission rates using a quasi-experimental approach to linear regression.
\end{abstract}

The second essay focused on identifying clusters of super-utilization across healthcare delivery systems. Specific aims of the second essay were: 1) to detect statistically significant clusters of concentrated readmission events attributed specifically to HRU by using the SatScanTM method for spatial scan statistics; 2) to explore overlap of identified clusters with population-based rates of readmission using chloropleth mapping to visually depict the relationship; and 3) to assess differences in the geographic distribution of readmission events attributed to HRU between urban and rural locations within cross-border areas using the Mann-Whitney U test to determine statistical significance.

The third essay focused on predicting risk of super-utilization across healthcare delivery systems using community demographic variables. Specific aims of the third essay were: 1) to assess the effect of rurality, income, and race on the presence of HRU using a logistic regression model; 2) to determine whether differences in model effects existed among regional healthcare delivery systems by including region as a class variable within the model; and 3) to evaluate whether differences in model effects existed at various concentrations of low-income households by performing decomposition 
analysis using contrasts based on percentiles of the distribution of low-income households.

Findings on the whole suggest that local healthcare delivery systems with high population-based rates of overall readmissions are also more likely to have underlying issues related to super-utilization. In fact, half of all inpatient readmission expenditures attributed to super-utilization across the study area were concentrated in local healthcare delivery systems in the 90th percentile of readmission rates. Unsurprisingly, clusters of super-utilization overlapped these local healthcare delivery systems with high rates. However, clusters of super-utilization were identified in all regions including some local healthcare delivery systems with rates no different or lower than the statewide per capita rate of readmissions. Furthermore, the highest risk of super-utilization occurred in areas with the highest concentration of low-income households, regardless of rural-urban designation, household race, or region.. 


\section{TABLE OF CONTENTS}

CHAPTER 1. INTRODUCTION

\section{CHAPTER 2. THE IMPACT OF SUPER-UTILIZATION ON POPULATION- BASED RATES OF READMISSION ACROSS HEALTHCARE DELIVERY

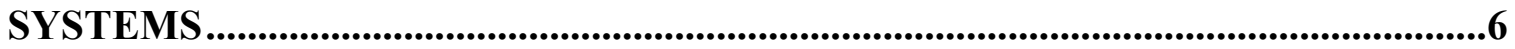

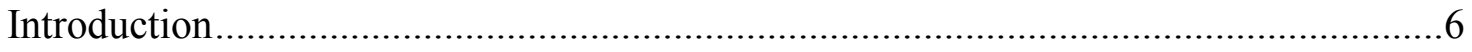

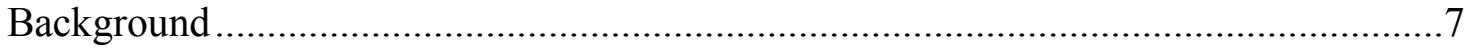

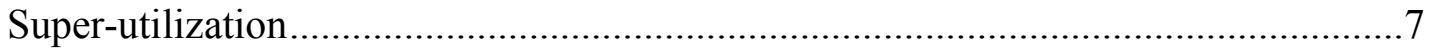

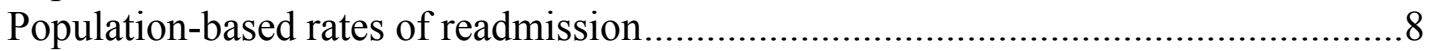

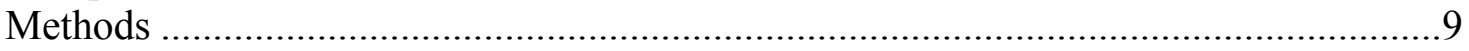

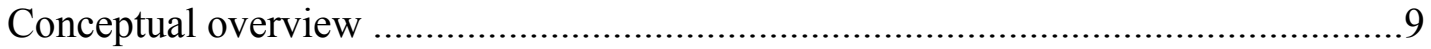

Data sources and study population …………………......................................10

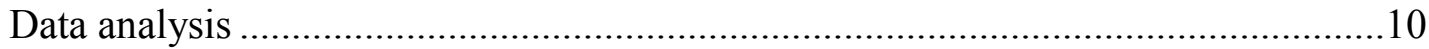

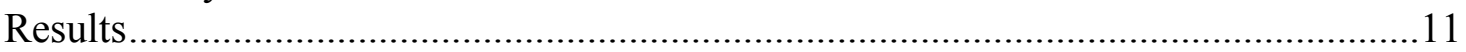

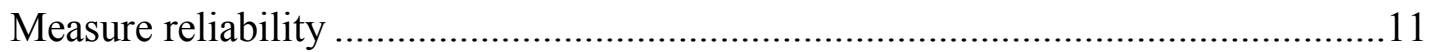

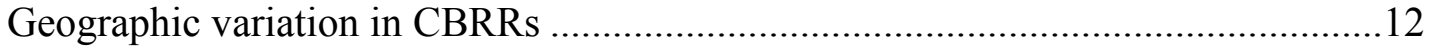

Beneficiaries, events, and costs associated with the stratified readmission

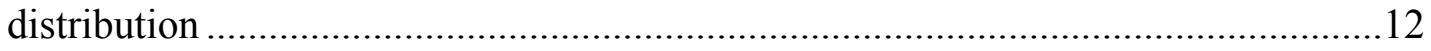

Impact of super-utilization on community-based rates of readmission ......................16

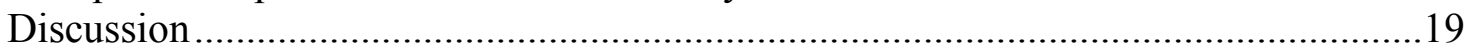

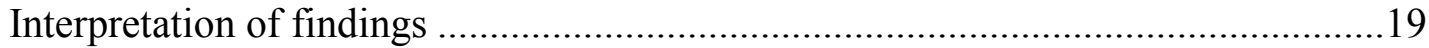

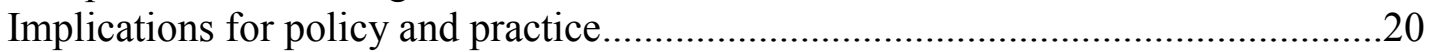

\section{CHAPTER 3. IDENTIFYING CLUSTERS OF SUPER-UTILIZATION}

ACROSS HEALTHCARE DELIVERY SYSTEMS USING SPATIAL SCAN

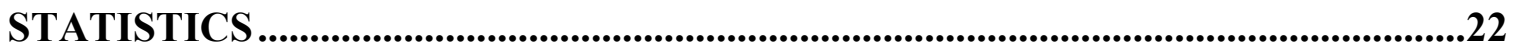

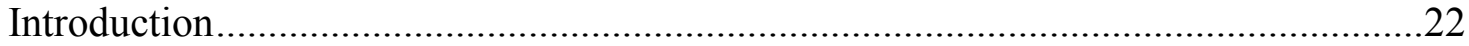

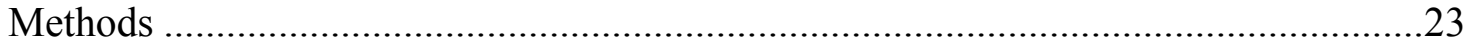

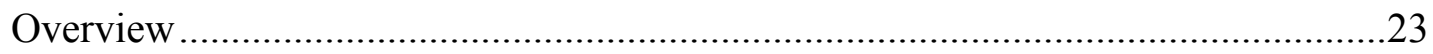

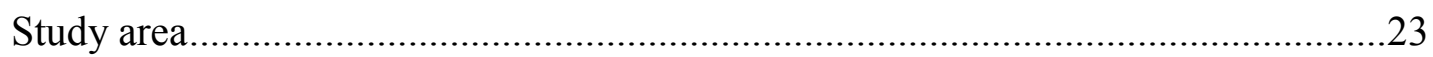

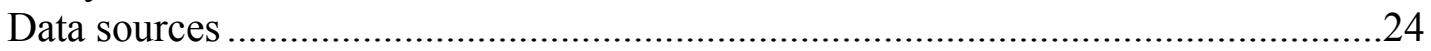

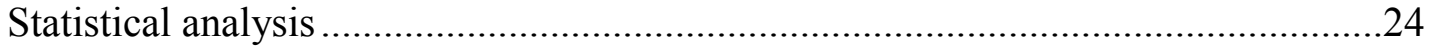

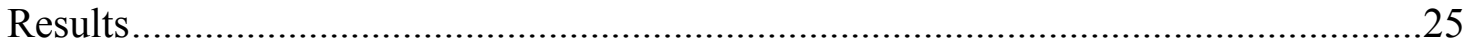

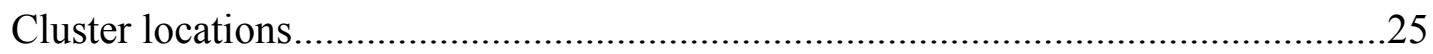

Rural and urban locations within clusters ..............................................................22

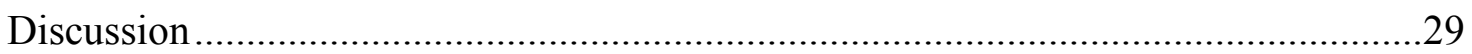

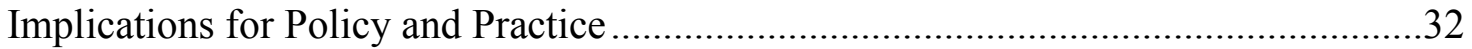

CHAPTER 4. CAN COMMUNITY DEMOGRAPHIC VARIABLES PREDICT THE RISK OF SUPER-UTILIZATION ACROSS HEALTHCARE DELIVERY

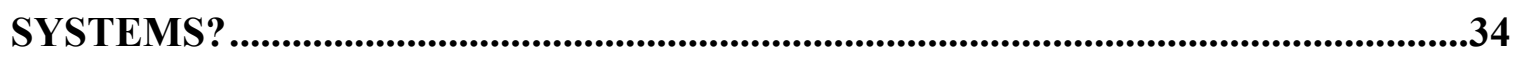

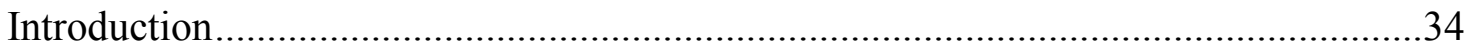

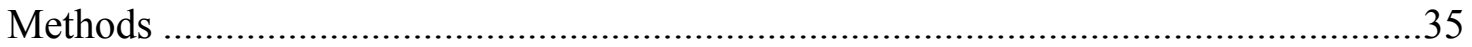




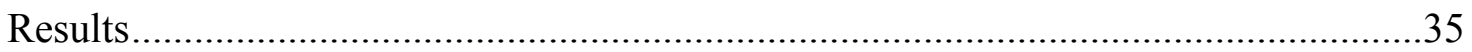

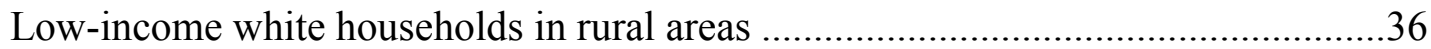

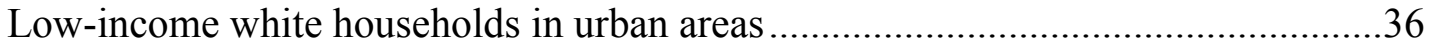

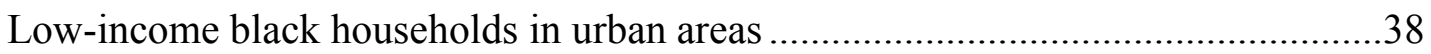

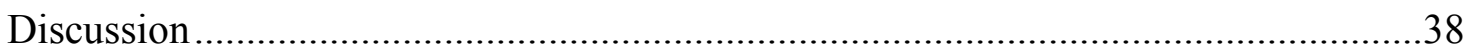

CHAPTER 5. SUMMARY ..............................................................................41

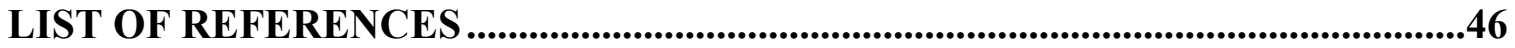

APPENDIX A. COMPARISONS OF COMMUNITY-BASED RATES OF READMISSION TO THE STATEWIDE PER CAPITA READMISSIONS ACROSS TENNESSEE HOSPITAL SERVICE AREAS .....................................50

APPENDIX B. DISTRIBUTION OF LOW-INCOME, WHITE HOUSEHOLDS

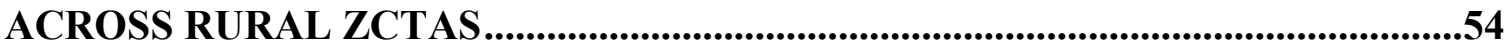

APPENDIX C. DISTRIBUTION OF LOW-INCOME HOUSEHOLDS BY RACE ACROSS URBAN ZIP CODE TABULATED AREAS ..............................55

VITA 


\section{LIST OF TABLES}

Table 2-1. Geographic distribution of community-based rates of readmission across

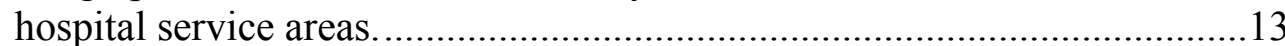

Table 2-2. Comparisons of readmission characteristics between hospital service areas with the lowest and highest community-based rates of readmission.

Table 2-3. Associations between the community-based rate of readmissions and readmission distributions stratified by number of readmissions per

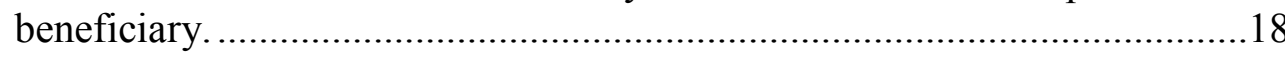

Table 3-1. Regional clusters of readmission events attributed to high repeat utilization .26

Table 4-1. Characteristics of zip code tabulated areas included in the study. .37

Table 4-2. Odds ratios for regional differences in the presence of high repeat utilization in urban, low-income, black households. 


\section{LIST OF FIGURES}

Figure 2-1. Comparison of community-based rates of readmission across Tennessee hospital service areas to per capita readmissions statewide. .......................14

Figure 2-2. Statewide distribution of readmission events, costs, and beneficiaries stratified by readmissions per beneficiary............................................... 15

Figure 3-1. Hot spots of super-utilization across Tennessee hospital referral regions....27

Figure 3-2. Distribution of readmission events across rural and urban ZCTAs within clustered areas of super-utilization in the Nashville HRR. .30

Figure 3-3. Distribution of readmission events across rural and urban ZCTAs within clustered areas of super-utilization in the Kingsport HRR. 


\section{CHAPTER 1. INTRODUCTION}

Since passage of the Affordable Care Act in 2010, policy makers and practitioners have made enormous efforts to reshape the American healthcare system to achieve higher quality care at a lower cost. The Triple Aim goals of improved population health, reduced costs, and improved patient experience set the national agenda for delivery system re-design (Berwick et al., 2008). Due to an annual price tag of $\$ 17$ billion dollars within the Medicare program, reducing unnecessary spending associated with preventable hospital readmissions was a primary target of early reform efforts (Jencks et al., 2009). With potential for considerable cost savings, readmissions were described as the perfect storm. As a result of substantial efforts under the Partnership for Patients initiative, the national Medicare readmission rate has decreased from 19\% to $17.5 \%$ (Gerhardt et al., 2013; Centers for Medicare \& Medicaid Services, 2014a). However, the modest decline in the readmission rate is falling short compared to the national goal of a $20 \%$ reduction (Centers for Medicare \& Medicaid Services, 2014b). The urgent imperative of achieving significant cost savings through lower inpatient hospital expenditures warrants further increased focus on options to achieve accelerated reductions in readmission rates.

Recently there has been increased attention on the small percentage of beneficiaries that account for disproportionately high inpatient utilization and costs. Medicare data has demonstrated that over half of all 30-day readmissions can be attributed to $30 \%$ of the readmitted beneficiary population with multiple readmissions per year (Brennan, 2012). In fact, in 2010 alone, $\$ 5.4$ billion or one-third of total readmission expenditures were spent on less than $1 \%$ of Medicare beneficiaries who readmitted three or more times per year. Average readmission expenditures were $\$ 3,254$ per patient across all beneficiaries compared to $\$ 67,837$ across beneficiaries with 3 or more readmissions per year. Furthermore, according to historical trend data, the number of readmissions has been increasing among beneficiaries with three or more readmissions per year while a decrease has occurred among beneficiaries with one or two readmissions per year. Hence, high levels of repetitive readmissions among relatively few beneficiaries is an expensive problem that seems to be growing.

Disproportionately high inpatient utilization and costs by a small percentage of patients is not a new concept in health services research (Anderson \& Steinberg, 1984). However, coining of the term 'super-utilizers' has rejuvenated interest in the highutilizing, high-cost patient population (Brenner, 2010). Growing literature on superutilizers informs characteristics associated with not only medical but also social complexity in this patient population. In addition to multiple chronic conditions, social complexity involves issues related to housing instability, behavioral health disorders, social isolation, and a history of traumatic adverse events (Brenner, 2010; Sandberg et al., 2014; Kronick et al., 2009; Felitti et al., 1998). Although traditional healthcare delivery systems are ill-equipped to meet these needs, innovative strategies that include a rapidly emerging evidence base for super-utilizer programs are advancing (Center for Health Care Strategies, 2015; Hasselman, 2013). Due to the potential to achieve exponential reductions in readmissions and associated costs with improvements to patient care, super- 
utilization may likely be the new perfect storm for action and attention in ongoing health reform initiatives.

Super-utilization is the focus of this three-essay dissertation. Although there is considerable knowledge about how to address common needs within super-utilizing populations, less is known about where super-utilization occurs and to what extent it exists across all communities. Using Tennessee as a demonstration state, these studies test new methods for assessing geographic variation in risk for super utilization across local healthcare delivery systems. For the purposes of this research, super-utilization is operationalized as high repeat utilization (HRU) and refers to readmission events and inpatient readmission expenditures associated with beneficiaries who experience four or more 30-day readmissions per year.

In the first essay, The Impact of Super-Utilization on Population-Based Rates of Readmission Across Health Care Delivery Systems in Tennessee, the question of where HRU occurs focuses on healthcare delivery systems with high population-based rates of overall readmission. The study builds on prior health services research that suggests high-utilizing, high-cost beneficiaries play an outsized role in areas with high readmission rates (Brennan, 2012). Theoretically, high readmission rates may be the result of a lot of patients readmitting once or fewer patients readmitting multiple times. Therefore, the hypothesis that areas with high population-based readmission rates are likely to have a high concentration of HRU as well is formally tested.

The second essay, Identifying Clusters of Super-Utilization across Healthcare Delivery Systems Using Spatial Scan Statistics, drills down to a smaller level of geography and identifies clusters of HRU within healthcare delivery systems. Hence, the question of where HRU occurs in the second essay focuses on unusual concentrations of readmission events attributed specifically to HRU across the population at risk. The study also builds on the first essay by visually depicting the spatial relationship between high population-based readmission rates and identified clusters through use of chloropleth mapping. In addition, it focuses on a specific pattern of high readmission rates found in the first essay among healthcare delivery systems that extend across state borders. Towards that end, the study determines whether rurality plays a significant role in clusters of HRU identified in cross-border areas.

The third and final essay, Can Community Demographic Variables Predict the Risk of Super-Utilization across Healthcare Delivery Systems, focuses on where HRU occurs in the context of rural and urban areas with low-income households across regional healthcare delivery systems. Using logistic regression modelling, the study determines the effect of community variables including rural-urban designation and lowincome households by race on the presence of HRU in a geographic area. Furthermore, differences between regions and by concentrations of low-income households are assessed as well.

The purpose of this overall body of research is to identify geographic areas, as opposed to individuals, at high risk for HRU. Since readmission events are attributed to 
the residence of the beneficiary rather than the facility at which care is received, the geographic areas at risk focus on where people live. This is important because where people live has a major influence on health outcomes due to economic, social, and physical environments that affect individuals' ability to make healthy choices (Robert Wood Johnson Foundation, 2011). In addition, where people live also influences the care they receive (Goodman et al., 2010).

Reporting overall rates of readmission can mask important differences between patient populations. Stratifying the distribution of readmissions by the number of readmissions per beneficiary is critical to understanding these differences (Brennan, 2012). Therefore, differences in patterns of utilization and cost attributed to beneficiaries with one, two, three, and four or more 30-day readmissions per year are highlighted. This is important because there is a tendency to treat all readmissions the same when in reality, beneficiaries who only readmit once per year are different from those who readmit four or more times per year (Brennan, 2012; Brenner, 2010). More importantly, all readmitted beneficiaries would not be expected to benefit similarly from a one-sizefits-all intervention strategy designed to reduce readmissions. Furthermore, the intensity and cost associated with implementing super-utilizer programs is likely higher compared to the majority of traditional care transition programs. Since relatively few readmitted beneficiaries fall into the super-utilizer category, identifying geographic areas with high risk for HRU can inform efficient allocation of these finite resources to areas with the highest potential for impact.

Essays one and two also report population-based measures of readmission that are typically calculated as the number of readmissions for every 1,000 Medicare beneficiaries (Jencks, 2014). Population-based readmission rates account for variation in the size of the population served by including all members of the population in the denominator. Unlike discharge-based rates of readmission, population-based rates are not dependent on the volume of total discharges or admissions. Therefore, population-based rates provide a fairer assessment of regional variation in rates of readmission as the rate is not obscured by differences such as local admitting practices of hospitals (Goodman, 2011; Jencks, 2014).

As mentioned previously, populations are defined geographically (e.g., where patients live) for the purposes of this research. Hence, population-based rates are specific to the population at risk across geographic areas. Of importance to note, these areas are aligned with geographically-bound healthcare delivery systems that are coterminous (e.g., share the same boundaries) and defined by natural patterns of hospital use within the study population (Wennberg, 1996). This is important in terms of extending accountability for population-based rates of readmission beyond the four walls of the hospital to multiple providers and settings across a healthcare delivery system. In addition, population-based outcomes reported at the healthcare systems level produces actionable data that can be used for purposes of quality improvement.

This research fills an important gap in the literature. No studies have used similar population-based readmission rates to assess geographic variation across healthcare 
delivery systems. Although geographic variation in population-based rates of readmission is publicly reported as an indicator of post-acute quality of care on the Dartmouth Atlas website, it measures the percent of patients readmitted within 30 days and cannot account for multiple readmission events per beneficiary (Dartmouth Atlas of Health Care, 2010). Medicare Quality Improvement Organizations (QIOs) have reported population-based rates similar to those used in this research; however, the rates are confined to select communities participating in QIO readmission reduction initiatives and are used to monitor change over time (Brock et al., 2013; Sugarman, 2015). Per capita readmissions, also similar to rates used in these studies, have been reported as well (Gerhardt et al., 2013). However, per capita readmissions are typically calculated at national or state levels whereas rates in this study are estimated across small area units of observation within local healthcare delivery systems.

The second essay contributes to the knowledge base related to medical hotspotting. The concept of medical hot-spotting, was highlighted by Atul Gawande in his New Yorker article titled, The Hot Spotters (2011). The article detailed efforts led by Dr. Jeffrey Brenner and the Camden Coalition of Healthcare Providers to use hospital billing data in order to identify high-cost patients with excessive use of hospital and emergency department services in Camden, New Jersey. Following Brenner's lead, several local communities have begun engaging in medical hot-spotting in order to provide outreach to super-utilizing patients and engage community stakeholders in transforming care processes. While previous efforts have focused on targeting individuals within a single community, this study employs cluster analysis techniques using validated statistical software to systematically identify hot-spots across all regional healthcare delivery systems.

The third essay adds to the body of literature on readmission risk prediction and health disparities. Traditionally, most risk prediction models for readmissions have demonstrated relatively poor predictive ability (Kansagara et al., 2011). Significant heterogeneity among patient populations and the omission of variables related to social determinants of health in most current models are factors that could improve future risk prediction models. The approaches to risk prediction used in this study account for both of these limiting factors. The approaches used are aligned with recent literature that includes community demographic variables in predictive modelling of readmission risk (Herrin et al., 2014; Kind et al., 2014; Moy et al., 2013). These prior studies have provided substantial evidence of the association between socioeconomically disadvantaged neighborhoods and increased risk of readmission. The third essay contributes new knowledge to the literature by assessing the effect of community demographic variables on risk for HRU specifically.

In summary, super-utilization is a costly problem that has not been resolved and may be growing. Fortunately, new knowledge has emerged that provides insight into how to address the issue. This research informs where to apply knowledge and resources for optimal impact to disproportionately high levels of utilization and spending attributed to readmissions by super-utilizers. However, addressing the issue will require new ways of thinking about how to predict, intervene upon, and create accountability for super- 
utilization within the context of overall readmission reduction initiatives. In addition, this body of research demonstrates innovative approaches for identifying geographic areas at high risk for super-utilization that can be scaled across all healthcare delivery systems. In turn, it can inform efforts aligned with the Triple Aim to address super-utilization at a national level. If efforts to reduce super-utilization are successfully implemented, there may be potential to achieve accelerated reductions in national readmission rates and significant cost savings. 


\section{CHAPTER 2. THE IMPACT OF SUPER-UTILIZATION ON POPULATION- BASED RATES OF READMISSION ACROSS HEALTHCARE DELIVERY SYSTEMS}

\section{Introduction}

In 2009, Jencks seminal study on rehospitalizations in the Medicare population put an annual price tag of $\$ 17$ billion dollars on unnecessary care associated with readmissions. With passage of the Affordable Care Act, the Medicare program set a national goal to achieve a $20 \%$ reduction in the rate of readmissions through coordinated efforts under the Partnership for Patients (P4P) initiative (Centers for Medicare \& Medicaid Services, 2014b). Despite enormous efforts including Hospital Engagement Networks, the Hospital Readmission Reduction Program, the Community-based Care Transition Program, and community-based readmission reduction initiatives of Medicare Quality Improvement Organizations, the national Medicare readmission rate decreased from $19 \%$ to $17.5 \%$ by the end of 2013 (Gerhardt et al., 2013; Centers for Medicare \& Medicaid Services, 2014a). Although promising, the urgent imperative of achieving significant cost savings through lower inpatient hospital expenditures warrants further increased focus on options to achieve accelerated reductions in readmission rates.

Recently, there has been a re-emergence of interest in the small percentage of patients who account for disproportionately high utilization and costs commonly referred to as 'super-utilizers' (Brenner, 2010). In 2010, \$5.4 billion or one-third of total readmission expenditures were spent on beneficiaries with 3 or more readmissions representing less than 1\% of all beneficiaries (Brennan, 2012). Average readmission expenditures across this population was $\$ 67,837$ per patient compared to $\$ 3,254$ per patient across all Medicare beneficiaries. In addition, trend data suggests that this disproportionate utilization and spending by relatively few beneficiaries may be a growing problem. Brennan's research also suggests that these super-utilizing beneficiaries may play an outsized role in areas with high overall rates of readmission. However less is known about where, in terms of healthcare delivery systems, patterns of high inpatient utilization occur and how they impact rates of readmission.

The overall purpose of this study is to identify areas at risk for super-utilization. The first aim of the study is to assess variation in population-based rates of readmissions across local healthcare delivery systems. This study also builds on Brennan's research that explores the role of high-utilizing, high-cost beneficiaries in areas with high rates of readmission (2012). Hence, a secondary aim of the study is to contrast the number of beneficiaries, readmission events, and inpatient readmission expenditures attributed to beneficiaries with one compared to four or more readmissions per year between local healthcare delivery systems with the lowest and highest readmission rates. Furthermore, the third and final aim is to formally assess the effect of the number of readmissions by beneficiaries with $1,2,3$, and 4 or more readmissions per year on overall readmission rates. Hence, this study improves understanding of the impact of super-utilization on population-based rates of readmission across healthcare delivery systems. 


\section{Background}

\section{Super-utilization}

Disproportionate inpatient utilization and spending by relatively few beneficiaries is not a new concept within health services research (Anderson \& Steinberg, 1984). Interest in this population has been rejuvenated by use of the term super-utilizers within the literature (Brenner, 2010). According to Medicare data, the largest volume of Medicare beneficiaries with 3 or more readmissions per year are over the age of 65 (Brennan, 2012). There is a commonly preconceived notion that these patterns of high utilization are associated with overutilization of inpatient care near the end of life among the frailest, elderly Medicare beneficiaries. However, Brennan's research showed that racial minorities and beneficiaries with dual eligibility for Medicare and Medicaid were over-represented among beneficiaries with 3 or more readmissions whereas beneficiaries over 65 years of age were not (2012). Furthermore, high-utilizing, high-cost beneficiaries are not unique to Medicare but are concentrated in publicly insured programs (Regenstein \& Andres, 2014). Regardless of payer type, several entities have documented the chronicity of high patterns of inpatient utilization by the same beneficiaries over multiple years (Brennan, 2012; Cohen, 2014).

Many of these patients with multiple readmissions tend to readmit following medical discharges rather than acute conditions following surgical discharge compared to privately insured counterparts indicating medical complexity due to multiple chronic conditions (Regenstein \& Andres, 2014). However, related literature on the superutilizing population suggests that these patients are not only likely to be medically but also socially complex (Brenner, 2010). In addition to multiple chronic conditions, high inpatient utilization has also been associated with issues such as housing instability, behavioral health disorders, social isolation, and a history of traumatic adverse events (Brenner, 2010; Sandberg et al., 2014; Kronick et al., 2009; Felitti et al., 1998). The medical and social complexity among this patient population is often coupled with a lack of primary and preventive care, absent or inadequate social services, and fragmented service delivery (Malone, 1995). There is a growing consensus that the super-utilizing population is at a disadvantage within the current healthcare delivery system (Hasselman, 2013).

The distinction between characteristics associated with super-utilizers and the majority of the readmitted patient population is important from an interventional standpoint. Common elements of most evidence-based care transition programs include improved medication management, symptom triage, self-management education, care coordination, and limited post-discharge follow up (Boutwell et al, 2009). Although these strategies are necessary, they are likely not sufficient to address the level of medical and social complexity of super-utilizing populations. Many communities across the country have begun implementing super-utilizer programs in order to address the unique needs of this sub-set of the population (Center for Healthcare Strategies, 2015; Hasselman, 2013). Additional components of these programs include extensive outreach 
with frequent face-to-face contacts; around-the-clock access to a comprehensive team including care managers, social workers, or community health workers; 'front-loading' of social services to meet basic needs; and inclusion of behavioral health services. Since programs targeted toward super-utilizers are of higher intensity compared to more traditional care transition programs geared toward the general inpatient population, it is essential to allocate finite resources to areas with the largest potential for impact.

\section{Population-based rates of readmission}

Discharge-based rates of readmission have been used to both compare hospital quality of care as well as to describe geographic variation in readmission rates (Bernheim et al., 2010). However, discharge-based rates are problematic for several reasons. First and foremost, there is widespread acknowledgement that readmission are a systems-level problem that extends beyond the four walls of a hospital. Policy makers are concerned that the current Hospital Readmission Reduction Program unfairly penalizes only hospitals for excess rates of readmission (Bocutti \& Casillas, 2015; Robert Wood Johnson Foundation, 2013). In addition, recent literature suggests that community demographics and health system characteristics account for more of the variation in 30day rates of readmission than hospital quality (Herrin et al., 2014).

Discharge-based readmission rates are also problematic at the community level because communities that are effective at reducing readmissions are also likely to reduce admissions overall resulting in changes to both numerator and denominator (Jencks, 2010). Preliminary data from the STAAR project demonstrated that hospital readmission rates can actually worsen or show no change as the number of readmissions goes down. As a result, entities like Medicare Quality Improvement Organizations have transitioned from discharge- to population-based rates in order to more accurately assess improvements in rates of readmission over time (Brock et al., 2013). Widespread use of population-based denominators have been advocated in order to stabilize rates of readmission (Jencks, 2014).

Finally, researchers involved in the Dartmouth Atlas of Healthcare Project have been using population-based denominators in order to assess regional variation in multiple healthcare utilization variables including hospitalization rates (Goodman, 2011). Accounting for variation in the regional size of a population allows a fairer comparison of hospital resource utilization between health systems as it does not obscure differences in admission or readmission rates due to local patterns of hospital use. Although a population-based readmission rate is included as an indicator of post-acute quality of care on the Dartmouth Atlas website, it measures the percent of patients readmitted within 30 days and cannot account for multiple events per beneficiary (Dartmouth Atlas of Health Care, 2010).

Expanding accountability for readmissions by using a population-based rate may be even more relevant to improving care for beneficiaries who experience high personal rates of readmission. Not only are these individuals highly likely to readmit to different 
hospitals, the complex care management needed necessitates a higher level of care coordination across providers, services, and settings (Hempstead et al., 2014; Hassleman, 2013). Hence in order to adequately address disproportionately high inpatient utilization and costs due to repeat readmissions, an increased focus on system level accountability for readmissions across the population served is needed.

\section{Methods}

\section{Conceptual overview}

Since few previous studies have investigated population-based rates of readmission using local healthcare delivery systems as the unit of analysis, a brief rationale of the rate developed for use in this study is provided. Important specifications relevant to the aims of this study include counting methodologies for what defines a numerator event, expression of the denominator, exclusions to the numerator based on planned readmissions, and description of geographic boundaries used as the unit of analysis.

The community-based rate of readmission (CBRR) used as the primary outcome in this study is a rate of 30-day, all-cause readmissions to any acute care hospital. Readmission events captured in the numerator were defined as all inpatient hospital admissions that occur within 30 days of discharge from a previous inpatient hospital admission. Hence, this rate captures multiple events per beneficiary in the numerator. This definition is consistent with counting methodology used by Medicare Quality Improvement Organizations within community-based readmission reduction initiatives (Brock et al., 2013). The population-based denominator used in this study included counts of all beneficiaries in the study population, not just those receiving inpatient care. As such, the overall rate was calculated as the total number of eligible readmission events divided by the total Medicare population using a multiplier of 1,000 .

Planned readmissions were excluded based on methodology established by Jencks in his seminal study on rehospitalizations among the Medicare population (2009). Planned readmissions were identified through an algorithm used to predict the probability of being planned based on an expected decay in the frequency of readmissions over time. The diagnosis-related group numbers representing the most common reasons for planned readmissions, as identified in the supplementary index to the article, were used to determine events excluded due to planned readmissions. In Jenck's study, approximately $10 \%$ of all readmissions were excluded as a result of care that could not be completed within a single hospitalization (2009). The only other exclusions to the numerator included same-day transfers and overlapping or invalid dates.

Geographic boundaries consistent with Dartmouth Atlas of Healthcare definitions allowed alignment between units of analysis and healthcare delivery systems rather than political boundaries such as a state or county (Wennberg, 1996). Hospital service areas 
(HSAs) are smaller units, akin to local healthcare delivery systems, that lie completely within larger hospital referral regions (HRRs). Whereas HSAs reflect patterns of local hospital use by residents, HRRs reflect patterns of referral for major cardiovascular surgical procedures and neurosurgery. HSAs were used as the primary unit of analysis; however, rates were also compared at the HRR level.

\section{Data sources and study population}

Data used in this observational study included 100\% Part A Medicare claims and enrollment data for the 2012 calendar year. Inpatient utilization and expenditures were attributed to the residence of the beneficiary rather than the hospital facility at which they occurred. Claims data were linked to HSAs and HRRs using 2012 zip code cross-walk files (Dartmouth Atlas of Health Care, 2012). Since zip codes refer to mail delivery routes, zip code tabulated areas (ZCTAs) that are generalized areal representations of United States Postal Service (USPS) ZIP Code service areas were used as the unit of observation (United States Census Bureau, 2010a). Hence, zip codes were aggregated to ZCTAs using zip to ZCTA cross walk files and spatially joined to shapefiles commonly used in GIS mapping applications (John Snow, Inc., 2012; United States Census Bureau, 2010b). The study population included all fee-for-service Medicare beneficiaries age 65 and older residing within Tennessee HRRs.

\section{Data analysis}

In order to assess variation in the population-based rate of readmissions across local healthcare delivery systems, one sample means testing using the $\mathrm{z}$ test statistic was used to determine whether the estimated rate for each HSA was significantly different from the 'state'- (e.g., HRR-) wide per capita rate. Model reliability was tested as well as the reliability of the HSA estimate itself. In order to test the intra-area reliability of the HSA estimate, coefficients of variation were calculated as the standard deviation divided by the mean. Coefficients of variation greater than one indicated over dispersion and a lowered confidence in the estimated mean due to relatively high standard errors.

Descriptive statistics using the percent of beneficiaries, readmission events, and inpatient readmission expenditures attributed to beneficiaries with one and four or more readmissions per year were used to contrast difference between HSAs in the 10th and 90th percentiles of readmission rates. In order to stratify the readmission distribution by the number or readmissions per beneficiary, beneficiaries were categorized as have one, two, three, or four or more 30-day readmissions per year. For the purposes of this study, high-cost, high-utilizing beneficiaries (e.g., super-utilizers) were defined as those with four or more 30-day readmissions per year. Categories used in this study were based on the Jenks natural breaks method of defining quantiles in the distribution of inpatient beneficiaries (Cromley \& McLafferty, 2002). This method optimizes natural divisions in the distribution so that groupings of readmitted patients are less arbitrary. 
In order to test the hypothesis that readmissions attributed to super-utilizing beneficiaries have a significant impact on the overall rate of readmissions, a linear regression model using the CBRR as the dependent variable and readmission distributions by beneficiaries with 1,2,3, and 4 or more 30-day readmissions per year as predictor variables. Due to the lack of normality across geographic distributions of readmission events, a quasi-quantitative approach was used that categorized variables based on quartiles of each distribution. The regression equation was evaluated at the approximate mean of each categorized distribution.

\section{Results}

A total of 1,118 zip codes were included within the Tennessee health referral region (HRR) boundary files. These zip codes were primarily in Tennessee but extended into seven additional states including Alabama, Arkansas, Georgia, Kentucky, Mississippi, North Carolina, and Virginia with hospital service areas (HSAs) within Tennessee HRRs. Nine zip codes located in Missouri and West Virginia were excluded with missing data due to omission from the cross-border claims data request. Fifty eight zip codes representing $4.5 \%$ of the total population were also excluded due to inadvertent omission of full or partial claims data associated with an HSA for which the state of the HSA was Tennessee (as opposed to one of the cross-border HSAs); however, the zip code of the city was located in a different state. These data were not recoverable at the time of this study. However, counts of beneficiaries from the denominator file within the 58 zip codes were removed as well in order to avoid falsely deflating rates of readmission. Additional exclusions of 36 zip codes without Medicare beneficiaries and 14 unique (non-residential) zip codes resulted in a final total of 1,001 zip codes statewide. Zip code data were aggregated to 848 zip code tabulated areas (ZCTAs) and 116 HSAs representing 942,512 Medicare beneficiaries, of whom full claims data were available for 133,269 beneficiaries receiving inpatient hospital services.

\section{Measure reliability}

The mean of the geographically distributed CBRR was estimated across ZCTAs for all HSAs with greater than one ZCTA. A moderately high correlation between the estimated HSA mean and the per capita rate calculated at the HSA level indicated that $72 \%$ of the variation in estimated rates could be explained by regional differences (R2 $=.721, \mathrm{n}=109, \mathrm{p}<.01)$. The coefficient of variation, a measure of intra-area reliability, was greater than one in 11 of 116 HSAs across all Tennessee HRRs. In order to reduce the impact of small area variation, 64 ZCTAs with insufficient sample sizes $(\mathrm{N}<56)$ to produce reliable estimates were excluded. This improved the intra-area reliability as well as the reliability of the overall model $(\mathrm{R} 2=.881, \mathrm{n}=107, \mathrm{p}<.01)$. 


\section{Geographic variation in CBRRs}

The mean CBRR across HSAs was 43 readmissions per 1,000 beneficiaries and the interquartile range was 23 readmissions per 1,000 beneficiaries (Table 2-1). The number of HSAs with rates lower, higher, or no different from the per capita average across Tennessee HRRs were 33, 36, and 38 respectively (Figure 2-1). Estimated means and results of significance testing for each HSA are shown in shown in Appendix $\mathbf{A}$.

Both the Chattanooga and Knoxville HRRs had the highest proportion of HSAs with rates lower than the state average. This was reflected in relatively low overall HRR rates. At the HRR level, Chattanooga's rate $(\mathrm{M}=29, \mathrm{SD}=12.3)$ was significantly lower than the state average, $\mathrm{z}=-39.851, \mathrm{p}<.001$. The Knoxville HRR rate $(\mathrm{M}=37, \mathrm{SD}=$ 31.5 ) was also lower than the state average, $z=-4.230, p<.001$. While rates were low around the primary HSAs in both regions, HSAs in the Kentucky border area of the Knoxville region were higher. Within the smallest HRR of Johnson City, only one HSA had a rate higher than the state average. However, the overall HRR rate $(\mathrm{M}=37, \mathrm{SD}=$ 16.0) was still lower than the state average, $z=-2.241, p=.025$. The rate within the primary HSA in the Memphis region was similar to the state average; however high HSA rates existed both in southern cross-border HSAs in Mississippi as well as to the north in the Tennessee HSA of Dyersburg. Overall, the Memphis HRR rate $(\mathrm{M}=43, \mathrm{SD}=32)$ was higher than the state average, $\mathrm{z}=22.578, \mathrm{p}<.001$. While rates in the primary HSAs of the Nashville and Kingsport regions were lower than the state average, high peripheral rates also existed in cross-borders HSAs in Kentucky and Virginia respectively. The HRR rates in both Nashville $(M=42, S D=20)$ and Kingsport $(M=57, S D=36)$ were also higher than the state average, $\mathrm{z}=50.486, \mathrm{p}<.001 ; \mathrm{z}=39.322, \mathrm{p}<.001$. The Jackson HRR demonstrated consistently high rates across the majority of HSAs including the primary HSA. The overall rate within the Jackson HRR $(\mathrm{M}=48, \mathrm{SD}=20)$ was higher than the state average as well, $\mathrm{z}=34.351, \mathrm{p}<.001$.

\section{Beneficiaries, events, and costs associated with the stratified readmission distribution}

Figure 2-2 shows the number of beneficiaries, readmission events, and inpatient readmission expenditures stratified by the number of readmissions per beneficiary across Tennessee HRRs. The majority ( $82 \%)$ of the inpatient population did not experience a 30-day readmission during the 2012 study period (Area A). Hence, approximately onefifth of the total inpatient population accounted for all readmission expenditures totaling nearly 309 million dollars in Medicare readmission spending (Areas B through E). Of the 24 thousand beneficiaries who did readmit, the majority (71\%) experienced readmission as a single incident during the year (Area B) and accounted for approximately half of all readmissions and associated expenditures. The other half is attributed to $5 \%$ of the total inpatient population readmitted more than once (Areas $\mathrm{C}$ through E). Beneficiaries with 4 or more readmissions per year represented $1 \%$ of the total inpatient population or $5 \%$ of all readmitted beneficiaries yet accounted for $14 \%$ of the total readmission expenditures (Area E). These 1,072 beneficiaries accounted for just 
Table 2-1. Geographic distribution of community-based rates of readmission across hospital service areas.

\begin{tabular}{lr}
\hline Characteristics & CBRR \\
\hline No. of HSAs & 116.00 \\
Per capita readmissions & 38.00 \\
Mean & 42.95 \\
Std. error of mean & 1.76 \\
Std. deviation & 18.91 \\
Skewness & 0.83 \\
Kurtosis & 1.35 \\
Minimum & 5.50 \\
10th percentile & 22.23 \\
25th percentile & 30.18 \\
Median & 40.65 \\
75th percentile & 52.71 \\
90th percentile & 68.17 \\
Maximum & 115.01 \\
\hline
\end{tabular}

Per capita readmissions is calculated at the state level as the total readmissions divided by the total Medicare beneficiary population using a multiplier of 1,000.

HSAs: hospital service areas; CBRR: community-based rate of readmission. 


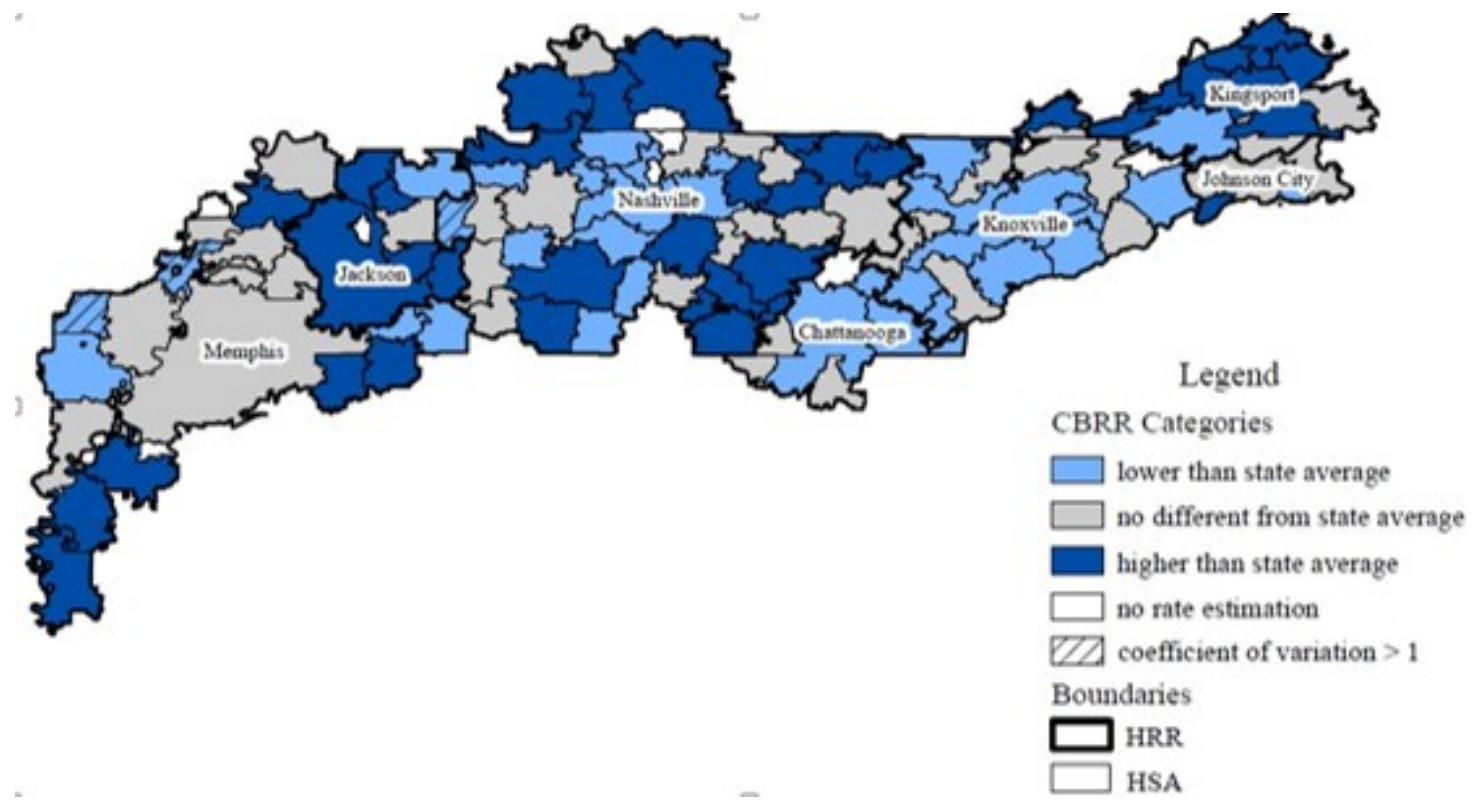

Figure 2-1. Comparison of community-based rates of readmission across Tennessee hospital service areas to per capita readmissions statewide. Map labels correspond to names of hospital referral regions.

CBRR: community-based readmission rate; HRR: hospital referral region; HSA: hospital service area. 


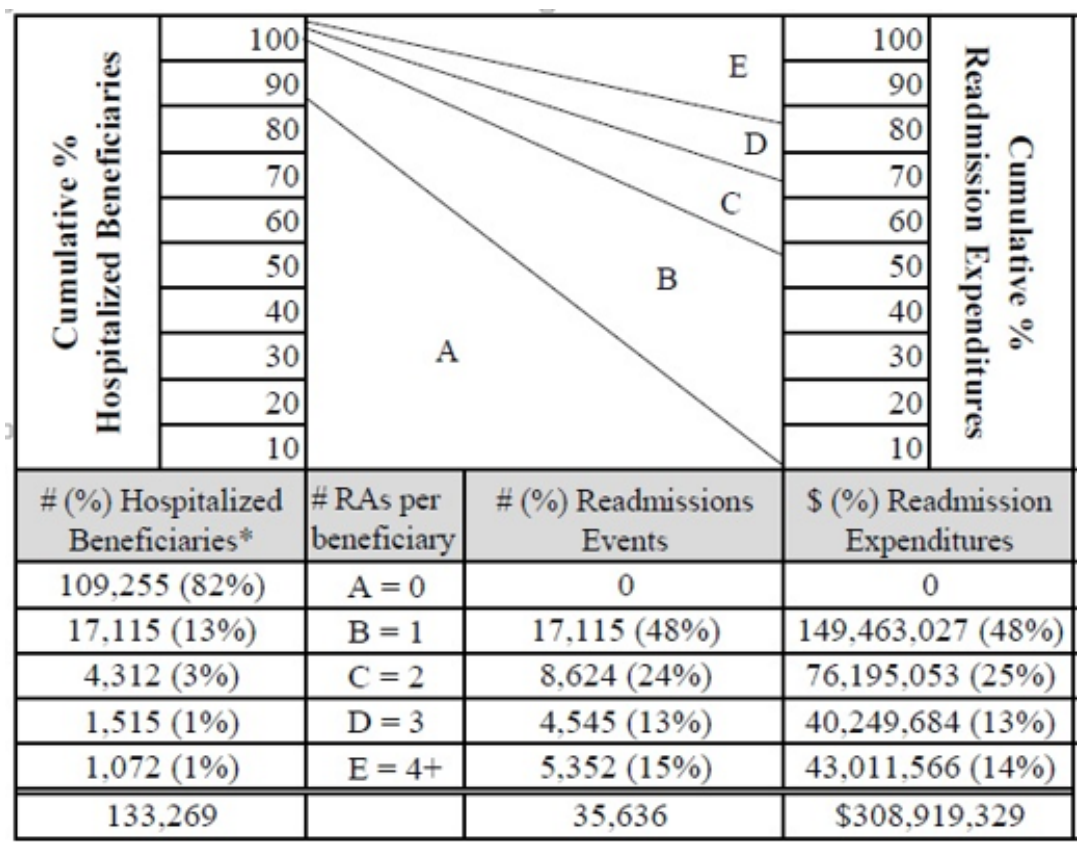

Figure 2-2. Statewide distribution of readmission events, costs, and beneficiaries stratified by readmissions per beneficiary.

Percentages of beneficiaries by stratified readmission categories shown include all beneficiaries receiving inpatient hospital care in the denominator. Percentages of beneficiaries by stratefied readmission categories including only readmitted beneficiaries are $71 \%, 18 \%, 6 \%$, and $5 \%$ for beneficiaries with $1,2,3$, and 4 or more readmissions per year, respectively.

RAs: readmissions. 
over 5,000 readmission events and 43 million dollars in inpatient readmission expenditures.

Comparisons of beneficiaries, events, and costs between HSAs in the 10th and 90th percentiles of estimated CBRRs are shown in Table 2-2. In order to make fairer comparisons, two HSAs with total Medicare populations less than 1,000 were excluded from the 10th percentile. All HSAs in the 90th percentile had populations greater than 1,000 beneficiaries. The CBRR at the 10th and 90th percentiles were 22 and 68 readmissions per 1,000 beneficiaries respectively. Descriptive statistics comparing 10 th and 90th percentiles of the estimated CBRR distribution demonstrated that the number of beneficiaries, readmission events, and inpatient readmission expenditures associated with beneficiaries who experience 4 or more 30 -day readmissions per year were higher among HSAs in the 90th compared to 10th percentiles of the distribution. Conversely, the number of beneficiaries, readmission events, and inpatient readmission expenditures associated with beneficiaries who experience a single 30-day readmission during the year were higher among HSAs in the 10th compared to 90th percentiles of the distribution. Furthermore, inpatient per capita spending on readmissions was \$616 among HSAs in the 90th percentile compared to $\$ 173$ among HSAs in the 10th percentile. Total inpatient readmission expenditures were nearly three times higher at $\$ 19.3$ million in the HSAs in the 90th percentile compared to $\$ 6.8$ million in the HSAs in the 10th percentile despite having $20 \%$ fewer beneficiaries (not shown).

\section{Impact of super-utilization on community-based rates of readmission}

Associations between the CBRR and readmission distribution stratified by the number of readmissions per beneficiary demonstrate an increasingly positive correlation as the number of personal readmissions per beneficiary increases (Table 2-3). Results of the regression model shown demonstrated that the composition of stratified readmission distributions has a significant impact on the overall rate, $\mathrm{F}(4,115)=18.490, \mathrm{p}<.001, \mathrm{R} 2$ $=.40$. Hence, $40 \%$ of the variation in the statewide CBRR can be explained by the relative composition of stratified readmission distributions. Furthermore, at the mean of the readmission distribution by beneficiaries with one readmission, there was a significant decrease of 17 readmissions per 1,000 beneficiaries, $\mathrm{t}(115)=-4.650, \mathrm{p}<.001$. The increase in CBRR at the mean of the readmission distribution by beneficiaries with two readmissions per year was not statistically significant. However, at the mean of the readmission distribution by beneficiaries with 3 readmissions per year, there was a significant increase of approximately 8 readmissions per 1,000 beneficiaries, $\mathrm{t}(115)=$ $3.300, p=.001$. The largest increase of nearly 10 readmissions per 1,000 beneficiaries occurred at the mean of the readmission distribution by beneficiaries with 4 or more readmissions per year, $\mathrm{t}(115)=4.45, \mathrm{p}<.001$. The strongest predictors of variation in the CBRR were the distribution of readmissions by beneficiaries with 1 readmission per year

and the distribution of readmissions by beneficiaries with 4 or more readmission per year. 
Table 2-2. Comparisons of readmission characteristics between hospital service areas with the lowest and highest community-based rates of readmission.

\begin{tabular}{|c|c|c|}
\hline Characteristics & 10th Percentile & 90th Percentile \\
\hline CBRR cut point & $25 / 1,000$ & $68 / 1,000$ \\
\hline Per capita readmission expenditures & $\$ 189$ & $\$ 573$ \\
\hline $\begin{array}{l}\% \text { readmitted beneficiaries with } 1 \\
\text { readmission/year }\end{array}$ & $72 \%$ & $63 \%$ \\
\hline $\begin{array}{l}\% \text { readmitted beneficiaries with } 4+ \\
\text { readmission/year }\end{array}$ & $4 \%$ & $8 \%$ \\
\hline $\begin{array}{l}\% \text { all readmissions by beneficiaries with } 1 \\
\text { readmission/year }\end{array}$ & $50 \%$ & $37 \%$ \\
\hline $\begin{array}{l}\% \text { all readmissions by beneficiaries with } 4+ \\
\text { readmission/year }\end{array}$ & $14 \%$ & $24 \%$ \\
\hline $\begin{array}{l}\% \text { readmission expenditures attributed to } \\
\text { beneficiaries with } 1 \text { readmission/year }\end{array}$ & $50 \%$ & $37 \%$ \\
\hline $\begin{array}{l}\% \text { readmission expenditures attributed to } \\
\text { beneficiaries with } 4+\text { readmission/year }\end{array}$ & $13 \%$ & $24 \%$ \\
\hline
\end{tabular}


Table 2-3. Associations between the community-based rate of readmissions and readmission distributions stratified by number of readmissions per beneficiary.

\begin{tabular}{|c|c|c|c|c|c|c|c|c|c|c|}
\hline \multirow[b]{2}{*}{ Model } & \multicolumn{2}{|c|}{$\begin{array}{c}\text { Unstandardized } \\
\text { Coefficients }\end{array}$} & \multirow{2}{*}{$\begin{array}{c}\begin{array}{c}\text { Standardized } \\
\text { Coefficients }\end{array} \\
\text { Beta }\end{array}$} & \multirow[b]{2}{*}{$\mathbf{t}$} & \multirow[b]{2}{*}{ Sig. } & \multicolumn{3}{|c|}{ Correlations } & \multicolumn{2}{|c|}{$\begin{array}{c}\text { Collinearity } \\
\text { Statistics }\end{array}$} \\
\hline & B & $\begin{array}{l}\text { Std. } \\
\text { Error }\end{array}$ & & & & $\begin{array}{l}\text { Zero- } \\
\text { order }\end{array}$ & Partial & Part & Tolerance & VIF \\
\hline (Constant) & 34.186 & 3.368 & & 10.149 & $<001$ & & & & & \\
\hline $1 \mathrm{RA} / \mathrm{yr}$ & -17.062 & 3.669 & -1.029 & -4.650 & $<.001$ & .146 & -.404 & -.342 & .110 & 9.056 \\
\hline $2 \mathrm{RAs} / \mathrm{yr}$ & 3.850 & 3.830 & .231 & 1.005 & .317 & .239 & .095 & .074 & .103 & 9.730 \\
\hline $3 \mathrm{RAs} / \mathrm{yr}$ & 7.738 & 2.345 & .513 & 3.300 & .001 & .392 & .299 & .243 & .224 & 4.464 \\
\hline $4+\mathrm{RAs} / \mathrm{yr}$ & 9.652 & 2.168 & .658 & 4.452 & $<.001$ & .447 & .389 & .327 & .248 & 4.035 \\
\hline
\end{tabular}

Dependent variable is the community-based rate of readmissions.

Predictor variables are distributions by quartiles of readmissions to beneficiaries with one, two, three, and four or more readmissions per year.

Significant differences are assessed at the $95 \%$ confidence level.

$\mathrm{RA}(\mathrm{s}) / \mathrm{yr}$ : readmission(s) per year. 


\section{Discussion}

\section{Interpretation of findings}

Community-based rates of readmission (CBRR) reported in this study cannot be interpreted within the context of publicly reported discharge-based rates of readmission. However, these rates are more comparable to per capita measures of readmission based on the CMS all-cause, facility-wide readmission rate or the all-cause rehospitalization rate used by Medicare Quality Improvement Organizations (QIOs) in community-based readmission reduction initiatives. According to these rates, in 2012 there were 53 readmissions per 1,000 Medicare beneficiaries (Sugarman, 2015; Gerhardt, et al., 2013). The average per capita CBRR calculated across all Tennessee HRRs was 38 readmissions per 1,000 Medicare beneficiaries during the same time period. The higher national rate is likely a reflection of differences in methodology rather than actual differences in utilization. This study was limited to Medicare beneficiaries age 65 and older; hence, does not include younger, dually eligible Medicare beneficiaries. Based on estimates of the number of Medicare beneficiaries less than 65 who are eligible for Medicaid, this represents approximately $12 \%$ of the entire Medicare population across Tennessee HRRs (Chronic Condition Data Warehouse, 2012). Since beneficiaries with dual eligibility are disproportionately represented among individuals with high personal rates of readmission, it is likely that inclusion would significantly increase the rates reported in this study. In addition, slight differences may also be attributed to the approximately $6 \%$ of all readmissions in this study that were excluded as planned readmissions.

However, the primary aim of this study was to assess variation in the geographic distribution of CBRRs across Tennessee HRRs. At the HRR level, the readmission rate ranged from a low of 29 readmissions per 1,000 beneficiaries in the Chattanooga region to a high of 57 readmissions per 1,000 beneficiaries in the Kingsport region. At the HSA level, the mean CBRR was 43 readmissions per 1,000 beneficiaries while the interquartile range was 23. In comparison to the per capita rate across TN HRRs, the number of HSAs with rates lower (33), higher (36), or no different (38) from the state average. These findings suggest substantial variation in CBRRs across Tennessee HRRs.

In addition, findings in this study were similar to prior research suggesting that super-utilizers play an outsized role in areas with high readmission rates (Brennan, 2012). This study expands upon Brennan's research by showing contrasts between HSAs in the 10th and 90th percentiles of population-based rates of readmission across regions of a state. In addition, results of the linear regression showed that readmissions attributed to HRU had a significant impact on overall readmission rates. The effect of readmissions associated with HRU was a significant increase in the overall rate while the effect of readmission attributed to beneficiaries who experience a single 30-day readmission during the year was a significant decrease in the overall rate.

Of further interest is the spatial pattern of lower rates in primary HSAs with increasing rates in peripheral areas including cross-border HSAs that was found in the 
Nashville, Kingsport and Memphis regions. Rurality and challenges to care coordination across state lines may be factors associated with these higher peripheral rates. Future research is needed in order to assess community variables associated with high population-based rates of readmission and presumably high repeat utilization. However, rates in all primary HSAs, specifically Memphis and Jackson, were not lower than the state average. This pattern may indicate clustering of repeat readmissions within urban areas as well. Drilling down utilization data to a lower level of geography may provide further insight into concentrated areas of super-utilization within local healthcare delivery systems.

In conclusion, local healthcare delivery systems with high rates of overall readmissions are more likely to have underlying issues related to HRU (e.g., disproportionate costs \& utilization attributed to super utilizers). In 2012, \$43 million dollars in inpatient readmission expenditures were spent by Medicare on beneficiaries age 65 and older across Tennessee HRRs. Approximately half of the total, or \$19.3 million, was concentrated in healthcare delivery systems that are outliers (e.g., 90th percentile of readmission rates). This represents significant potential for Medicare cost savings with targeting outliers. The cost savings would likely be much greater with inclusion of dually eligible beneficiaries less than 65 years of age.

\section{Implications for policy and practice}

Findings from this study demonstrate the capacity to use population-based rates of readmission to make fair comparisons in hospital resource utilization between healthcare delivery systems. The Centers for Medicare \& Medicaid Services could progress from using discharge-based facility rates to population-based rates in order to encourage accountability for rates of readmission across providers and settings in a geographicallydefined healthcare delivery system. This option is aligned with current recommendations from experts in the field of measurement and performance reporting (Jencks, 2014).

There are multiple opportunities to align existing and future policies to encourage healthcare delivery systems with high rates of readmission to address super-utilization. This is particularly important among delivery systems with the highest rates of readmission. One example would be to use all-cause, population-based rates of readmission to assess penalties among local healthcare delivery systems with excessive rates through the Hospital Readmission Reduction Program. This alternative has the potential to impact delivery systems who are outliers with the highest rates of populationbased readmissions and therefore, those faced with super-utilizer challenges.

All healthcare delivery systems will benefit from ongoing readmission reduction activities. However, in response to local challenges, some may benefit more than others by investing in super-utilizer programs. Local healthcare delivery systems with the highest population-based readmission rates should consider implementing these types of interventions within an overall readmission reduction strategy. On the national level, the majority of readmission reduction initiatives to date have not emphasized strategies 
targeted toward super-utilizers (Mathematica, 2014; Econometrica, 2013; Ventura et al., 2010). Instead, these initiatives have encouraged replication of more traditional hospitaland community-based care transition interventions geared toward the general inpatient population including evidence-based programs like the $\mathrm{CTI}^{\mathrm{TM}}$ model. As the evidencebase for models targeting super-utilizers grows, these interventions should be included in national initiatives like the Community-based Care Transitions Program. Towards that end, expanding studies using methods similar to all healthcare delivery systems can inform preferred selection for participation in future national initiatives. 


\section{CHAPTER 3. IDENTIFYING CLUSTERS OF SUPER-UTILIZATION ACROSS HEALTHCARE DELIVERY SYSTEMS USING SPATIAL SCAN STATISTICS}

\section{Introduction}

The concept of medical hot-spotting has received substantial national interest largely as a result of Atul Gawande's New Yorker article titled, The Hot Spotters (2011). The article highlighted the analogy between crime mapping and the use of healthcare cost and utilization data in order to target resources to areas where quality of care could be improved. Early efforts to identify medical hot-spots were led by Dr. Jeffrey Brenner who performed neighborhood-level analysis of utilization and cost data using a citywide health database containing medical billing data from three local hospitals in Camden, New Jersey (Brenner, 2010). This data was used not only to provide outreach to highutilizing, high-cost patients, but also to engage community stakeholders in ongoing transformation of the local health delivery systems. Based on this early work, multiple entities across the country have begun engaging in medical hot-spotting efforts in their own communities (Robert Wood Johnson Foundation, 2012).

Underlying the concept of medical hot-spotting is the well-known fact that a small percentage of all patients account for disproportionately high inpatient utilization and costs (Anderson \& Steinberg, 1984). The intensity of services required to adequately address needs among these 'super-utilizers' is higher compared to the majority of the patient population (Hasselman, 2013). Fortunately, a strong evidence base for superutilizer programs is rapidly emerging (Center for Healthcare Strategies, 2015). Because there are relatively few super-utilizing beneficiaries, knowing where these patients are located is critical to allocating finite resources to high-risk areas and optimizing the organization of service delivery. While previous efforts have focused on targeting individuals within a single community, this study uses a systematic approach to identifying high-risk areas within healthcare delivery systems across all regions of the state.

The approach to medical hot-spotting used in this study is unique. It demonstrates the use of cluster analysis techniques using retrospective claims data in order to identify geographic areas with increased risk for super-utilization. Intuitively, social and economic conditions exist that predispose patterns of super-utilization. Recent literature provides substantial evidence of the association between socioeconomically disadvantaged neighborhoods and increasing risk of readmission (Herrin et al., 2014; Kind et al., 2014; Moy et al., 2013). Since neighborhood demographics typically do not rapidly change, using claims data has high potential for identifying hot spots that are likely to be stable over an extended period of time.

The primary aim of this study is to detect significant clusters of super-utilization using a validated statistical software program $\left(\operatorname{SaTScan}^{\mathrm{TM}}\right)$. Within a spatial context, clusters are defined as unusual concentrations of health events across a geographic area (Cromley \& McLafferty, 2002). For the purposes of this study, super-utilization is 
operationally defined as high repeat utilization (HRU) and quantified as 30-day readmission events attributed to Medicare beneficiaries with four or more readmissions per year. The research also builds on prior findings that describe an outsized role of beneficiaries with multiple readmissions per year in healthcare delivery systems with high readmission rates (Brennan, 2010). Because this study identifies clusters at a lower level of geography, it can be used to 'drill down' high rates to specific areas within the delivery system. Toward that end, the second aim is to explore the relationship between population-based readmission rates and identified clusters by using ArcGIS mapping software to visually depict overlap. The study also furthers the investigation of rurality in areas with high population-based rates of readmission located in cross-border areas (e.g., service delivery areas that cross state lines). Hence, the third and final aim of this study is to assess differences in the geographic distribution of readmission events attributed to HRU between urban and rural locations within high-risk cross-border areas using nonparametric tests of statistical significance.

\section{Methods}

\section{Overview}

Due to the unique application of spatial scan statistics to medical hot-spotting, a brief overview of spatial scan statistics is provided. The spatial scan statistic was developed by Martin Kulldorf and has been widely used to identify crime hot spots as well as other events related to disease, injury, accident, and environmental occurrences. The general statistical theory behind the spatial scan statistic used has been described in detail by Kulldorff (1997). The spatial scan statistic is generated by gradual scanning of an infinite number of geographical circles varying in size up to a certain percent (e.g., $50 \%$ ) of the population at risk across the study area. Numbers of observed and expected events inside and outside of each scanned circular window are compared when calculating the log likelihood ratio for each potential cluster. It tests the null hypothesis (e.g., spatial randomness) against the alternative hypothesis that risk of events is different within the circle compared to outside. The statistical significance of the likelihood ratio is tested through a large number of replications of the data set under the null hypothesis in a Monte Carlo simulation in order to assess the statistical stability of identified clusters. The likelihood ratio for each replica is computed and the result is significant at the 0.05 level if the value of the real data set is among the top $5 \%$ of all the values including the replicas. Hence, Kulldorf's spatial scan statistic is able to detect multiple clusters of different sizes.

\section{Study area}

The geographic boundaries used to define the study area are consistent with Dartmouth Atlas of Health Care's definition of hospital service areas (HSAs) contained within larger health referral regions (HRRs) (Wennberg, 1996). These boundaries are 
defined by natural patterns of hospital use among Medicare beneficiaries. There are seven Tennessee HRRs that extend into Alabama, Arkansas, Georgia, Kentucky, Mississippi, North Carolina, and Virginia. Each HRR was evaluated separately for the clustering of events. The study population residing within Tennessee HRRs totaled 942,512 fee-for-service Medicare beneficiaries age 65 and older.

\section{Data sources}

Data used in this study included 100\% Part A Medicare claims and enrollment data during the 2012 observation period. The attribution of 30 -day readmission events to the residence of the beneficiary rather than the hospital at which they occurred is described in he Methods section of Chapter 2. The number of readmission events among beneficiaries with four or more 30-day readmissions per year were aggregated to zip code tabulated areas (ZCTAs) as the primary unit of analysis. Claims data were linked to geographic boundary data using publicly available cross walk files and spatially joined to shapefiles created using TIGER/Line ${ }^{\circledR}$ Shapefiles (The Dartmouth Atlas of Health Care, 2012; John Snow, Inc., 2012; United States Census Bureau, 2010). Cluster analysis was performed using SaTScanTM, Version 9.4 software loosely coupled with ArcMap, Version 10.2 GIS software for visual presentation.

\section{Statistical analysis}

For the purposes of this study, spatial analysis using the spatial scan statistic was based on a Poisson model due to the relatively small sub-set of the beneficiary population with four or more readmissions per year. In addition, the discrete model is well-suited to aggregate location data. Under a discrete Poisson model, the scan statistic adjusts for the uneven geographical density of a population. Therefore, the expected number of events in each region is proportional to the size of the region's total Medicare population. Since methods used in this study scanned for a high proportion of events within the population, the specific alternative hypothesis used was that the estimated risk of events associated with HRU across the population within each cluster is greater than the estimated risk of events associated with HRU across the remainder of the region's population outside of the cluster. A maximum spatial cluster size of $50 \%$ of the population at risk was used. The $\mathrm{p}$ values were obtained by Monte Carlo simulations using 999 replications. Hierarchical, non-overlapping clusters with statistical significance at the 0.05 probability level were reported.

Exploratory spatial analysis visually depicting the relationship between population-based rates of readmission and statistically significant clusters were performed by creating multi-layer chloropleth maps. Rates at the HSA level reported in Chapter 2 were used as the base layer of the map. A second layer of statistically significant clusters, as determined through $p$ values generated by the spatial scan statistic, were mapped using location IDs (e.g., ZCTAs) contiguous with HSA boundaries. 
In order to assess differences in readmission events attributed to high repeat utilization between rural and urban areas in cross-border areas, the most likely cluster in both the Nashville and Kingsport HRRs were defined as study areas and evaluated separately. Nashville and Kingsport most likely clusters were chosen due to the size of the cluster and ability to detect significant differences. ZCTAs were categorized as urban or rural based on United States Census Bureau's designation of urban and non-urban (e.g., rural) locations (2010c). More specifically, regardless of whether either the entire ZCTA was contained within a larger urbanized area or a portion of the ZCTA was identified as an urban cluster, the ZCTA was designated as urban. All remaining ZCTAs were considered rural. Differences in readmission events associated with HRU between rural and urban ZCTAs within most likely clusters of cross-border areas was performed using a Mann-Whitney $U$ test due to significant heteroscedasticity of variances between rural and urban distributions of HRU.

\section{Results}

\section{Cluster locations}

Across all Tennessee HRRs, a total of 24 statistically significant clusters of readmission events associated with high repeat utilization (HRU) were identified. Characteristics of each cluster, including the relative risk and $p$ values, are provided in Table 3-1. Figure 3-1 shows the clusters in conjunction with previously reported population-based rates of overall readmission across hospital service areas (HSAs). The majority of clusters overlapped with areas of high overall readmission rates. This finding was most evident in the Jackson, Nashville, and Kingsport HRRs. However, several clusters existed in areas that had readmission rates that were no different than the state average. For example, two small clusters were located in the central portion of the primary hospital service area within the Memphis region. Very few clusters were located in areas with rates lower than the state average. These clusters were limited to the Chattanooga and Knoxville regions, both of whom had the greatest number of HSAs with rates lower than the state average.

The population-based rate of HRU throughout the Chattanooga HRR was 312 readmissions per 100,000 Medicare beneficiaries. Three clusters were identified within the region representing $76 \%$ of all HRU events in the HRR. Inpatient readmission expenditures associated with HRU were approximately $\$ 1.6$ million across all clustered areas of the region. The most likely cluster within the region was located in one HSA in the eastern portion of the region. In the southern portion of the region, another cluster was located in the primary HSA extending into an HSA in Georgia. On the western edge of the region, the third cluster spanned both a Tennessee and Alabama HSA.

In the Jackson HRR, the population-based rate of HRU was 694 events per 100,000 beneficiaries. Three clusters were also identified within the Jackson HRR representing $46 \%$ of the region's total HRU events. The total inpatient readmission 
Table 3-1. Regional clusters of readmission events attributed to high repeat utilization.

\begin{tabular}{lccccccc}
\hline \multicolumn{1}{c}{ HRR } & $\begin{array}{c}\text { Directional } \\
\text { Designation }\end{array}$ & $\begin{array}{c}\# \\
\text { ZCTAS }\end{array}$ & Observed & Expected & Population & $\begin{array}{c}\text { Relative } \\
\text { Risk }\end{array}$ & P Value \\
\hline Chattanooga & $\mathrm{E}$ & 6 & 96 & 41.89 & 13,396 & 3.01 & $<.001$ \\
Chattanooga & $\mathrm{S}$ & 13 & 86 & 54.50 & 17,429 & 1.85 & .001 \\
Chattanooga & $\mathrm{W}$ & 3 & 21 & 8.48 & 2,711 & 2.60 & .019 \\
Jackson & $\mathrm{C}$ & 4 & 78 & 35.95 & 5,166 & 2.52 & $<.001$ \\
Jackson & $\mathrm{N}$ & 1 & 17 & 3.00 & 431 & 5.92 & $<.001$ \\
Jackson & $\mathrm{E}$ & 6 & 64 & 33.89 & 4,870 & 2.10 & $<.001$ \\
Johnson & & & & & & & \\
City & $\mathrm{SW}$ & 4 & 71 & 27.85 & 4,152 & 3.11 & $<.001$ \\
Kingsport & $\mathrm{N}$ & 49 & 374 & 226.09 & 23,921 & 2.52 & $<.001$ \\
Kingsport & $\mathrm{SE}$ & 4 & 58 & 31.73 & 3,357 & 1.91 & .003 \\
Knoxville & $\mathrm{NE}$ & 10 & 99 & 16.36 & 3,735 & 6.68 & $<.001$ \\
Knoxville & $\mathrm{E}$ & 20 & 212 & 117.47 & 26,821 & 2.05 & $<.001$ \\
Knoxville & $\mathrm{SW}$ & 1 & 34 & 9.52 & 2,174 & 3.67 & $<.001$ \\
Knoxville & $\mathrm{SE}$ & 1 & 18 & 3.16 & 722 & 5.79 & $<.001$ \\
Knoxville & $\mathrm{NW}$ & 2 & 15 & 4.31 & 983 & 3.53 & .025 \\
Memphis & $\mathrm{S}$ & 25 & 128 & 40.09 & 7,300 & 3.55 & $<.001$ \\
Memphis & $\mathrm{N}$ & 18 & 139 & 71.13 & 12,953 & 2.12 & $<.001$ \\
Memphis & $\mathrm{C}$ & 1 & 40 & 17.42 & 3,172 & 2.35 & .002 \\
Memphis & $\mathrm{C}$ & 1 & 65 & 35.17 & 6,405 & 1.91 & .003 \\
Nashville & $\mathrm{N}$ & 38 & 343 & 183.35 & 29,868 & 2.05 & $<.001$ \\
Nashville & $\mathrm{NE}$ & 15 & 129 & 44.89 & 7,312 & 3.00 & $<.001$ \\
Nashville & $\mathrm{S}$ & 15 & 173 & 77.61 & 12,643 & 2.35 & $<.001$ \\
Nashville & $\mathrm{C}$ & 4 & 112 & 59.69 & 9,724 & 1.93 & $<.001$ \\
Nashville & $\mathrm{ME}$ & 9 & 40 & 13.11 & 2,135 & 3.09 & $<.001$ \\
Nashville & $\mathrm{MW}$ & 1 & 42 & 21.10 & 3,437 & 2.01 & .048 \\
\hline
\end{tabular}

For purposes of cluster identification within regions, each cluster is given a directional designation based on cardinal directions (e.g., north, east, south, west).

C: central; ME: mideast; MW: midwest; ZCTA: zip code tabulated area; HRR: hospital referral region. 


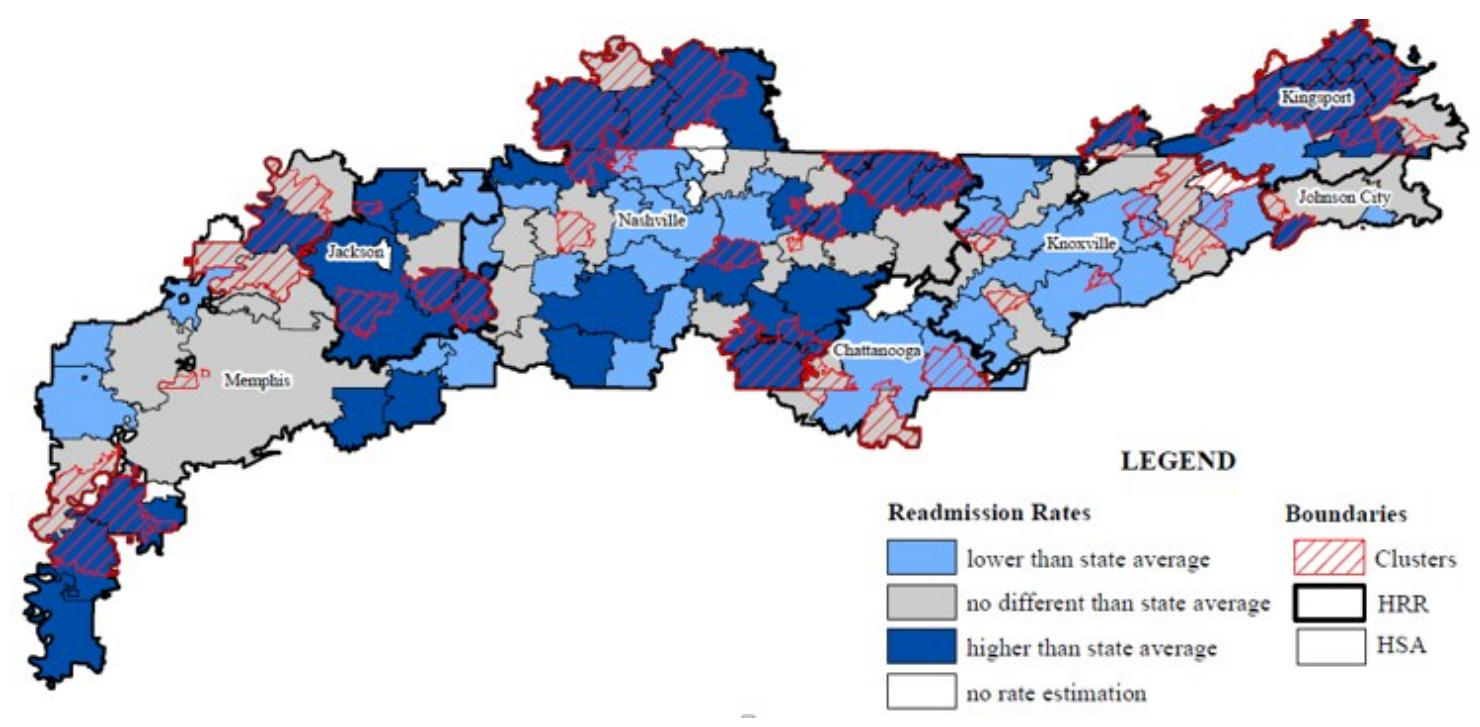

Figure 3-1. Hot spots of super-utilization across Tennessee hospital referral regions.

Readmission rate categories are based on comparisons of population-based readmission rates across hospital service areas to statewide per capita readmissions. Clusters represent readmission events attributed to beneficiaries with four or more 30-day readmissions per year. Labels correspond to names of Tennessee hospital referral regions.

HRR: hospital referral region; HSA: hospital service area. 
expenditures across the region's clustered areas were approximately $\$ 1.2$ million. The most likely cluster was centrally located in the primary HSA. Directly to the east, another cluster was located across two HSAs. The final cluster, comprised of a single rural ZCTA, was located in within an HSA in the northern portion of the region.

The Johnson City HRR's population-based rate HRU was 669 events per 100,000 beneficiaries. Only one cluster was identified within the HRR in the southwest portion of the region spanning the primary and one additional HSA. This cluster represented only $26 \%$ of the region's total HRU events. Inpatient readmission expenditures associated with the clustered area totaled approximately $\$ 460$ thousand. Within the neighboring Kingsport HRR, the population-based rate of HRU was 943 events per 100,000 beneficiaries. Two statistically significant clusters were identified that represented $66 \%$ of the region's total HRU events and accounted for approximately $\$ 3.4$ million in inpatient readmission expenditures. The most likely cluster to the north of the Kingsport HSA spanned 9 different Virginia HSAs in addition to one HSA in Kentucky. Adjacent to the most likely cluster, a smaller rural cluster to the east spanned two Virginia HSAs.

The Knoxville HRR had a population-based rate of HRU of 437 events per 100,000 beneficiaries. Within the Knoxville HRR, five clusters were identified representing $42 \%$ of all HRU events within the region. The regional cost of inpatient readmission expenditures attributed to HRU within clustered areas was $\$ 2.7$ million. The most likely cluster in the northeastern portion of the region was located across three HSAs including two in Kentucky and one in Tennessee. The largest cluster to the east spanned six Tennessee HSAs. Three smaller yet distinct clusters were also identified. Two single-ZCTA urban clusters to the southwest and southeast were both located Tennessee HSAs. Another small, rural cluster to the northwest portion of the region was located across two Tennessee HSAs.

The population-based rate of HRU in the Memphis HRR was 548 events per 100,000 beneficiaries. Four clusters were identified in the Memphis region. Together these clusters represented $40 \%$ of all regional HRU events and accounted for $\$ 3.4$ million in inpatient readmission expenditures. In the southern portion of the region, the most likely cluster was located in three HSAs including two in Mississippi and one in Arkansas. In the northern portion of the region, another cluster spanned three Tennessee HSAs. Two smaller, single-ZCTA urban clusters were identified in the central portion of the primary HSA.

In the Nashville HRR, the population-based rate of HRU was 613 events per 100,000 beneficiaries. A total of six distinct clusters were identified that accounted for $42 \%$ of the region's total HRU events and $\$ 6.4$ million in inpatient readmission expenditures. In the northern portion of the region, the most likely cluster was located across four Kentucky HSAs and two Tennessee HSAs. Toward the northeast NashvilleKnoxville border, another cluster spanned four Tennessee HSAs. Three smaller clusters were all located across Tennessee HSAs in the midregion area. The mideast cluster was located across three HSAs. The most centrally located cluster was within a single HSA. 
The midwest cluster was located within a single urban ZCTA. In the southern portion of the region on the Chattanooga border, the final cluster spanned three Tennessee HSAs.

\section{Rural and urban locations within clusters}

Large, predominantly rural clusters were the most likely clusters of readmission events associated with HRU in the northern portion of the Kingsport and Nashville HRRs. These areas were of particular interest due to high population-based rates of overall readmissions associated with cross-border areas. As the scan window increased in size over less densely populated areas, a pattern of fewer events dispersed throughout many rural locations within these two clusters was expected. However, Figures 3-2 and 3-3 show that the highest concentration of events associated with HRU were within urban ZCTAs of the most likely clusters in both regions. In addition, events were not evenly distributed throughout rural ZCTAs in these clusters. Several rural ZCTAs neighboring highly concentrated urban ZCTAS also had relatively high concentrations of events. However, not all rural ZCTAs within these clusters had an elevated risk of events. Inclusion of these areas within the clusters was likely due to both small populations and uncertainty of the exact boundaries of the cluster.

In the most likely clusters within both the Kingsport and Nashville regions, there were $64 \%$ fewer urban compared to rural ZCTAs. Despite fewer locations, more readmission events occurred in urban ZCTAs compared to rural ZCTAs in both regions as well. A Mann-Whitney U test was performed to evaluate the hypothesis that rural ZCTAs actually had fewer readmission events associated with HRU compared to urban ZCTAs in these predominantly rural clusters. The results of the test in the Kingsport most likely cluster were in the expected direction and significant, $\mathrm{z}=-3.715, \mathrm{p}<.001$. Rural areas in the Kingsport cluster had an average rank of 20.72, while urban ZCTAs had an average rank of 36.85. Similar results were found in the Nashville most likely cluster, $\mathrm{z}=-3.526, \mathrm{p}=.001$. Rural ZCTAs in the Nashville cluster had an average rank of 16.09, while urban ZCTAs had an average rank of 29.05.

\section{Discussion}

This study identified several clusters of readmission events attributed to high repeat utilization (HRU) within all health referral regions (HRRs) across the State of Tennessee. Based on prior research, it is not surprising that the majority of clusters overlapped hospital service areas with high overall rates of readmission. However, not all clusters were located in areas with high overall readmission rates. In addition clusters varied by relative risk, size, and location. For example, the cluster in the northeast portion of the Knoxville HRR had the highest risk of HRU $(\mathrm{RR}=6.68)$ across all clusters. Clusters ranged from a large, predominantly rural cluster in the cross-border area of the Kingsport HRR to small, single-ZCTA clusters in the urban core of the Memphis HRR. However, these very different clusters had a similar risk of HRU events that was approximately two times higher than areas outside of the clusters within each 


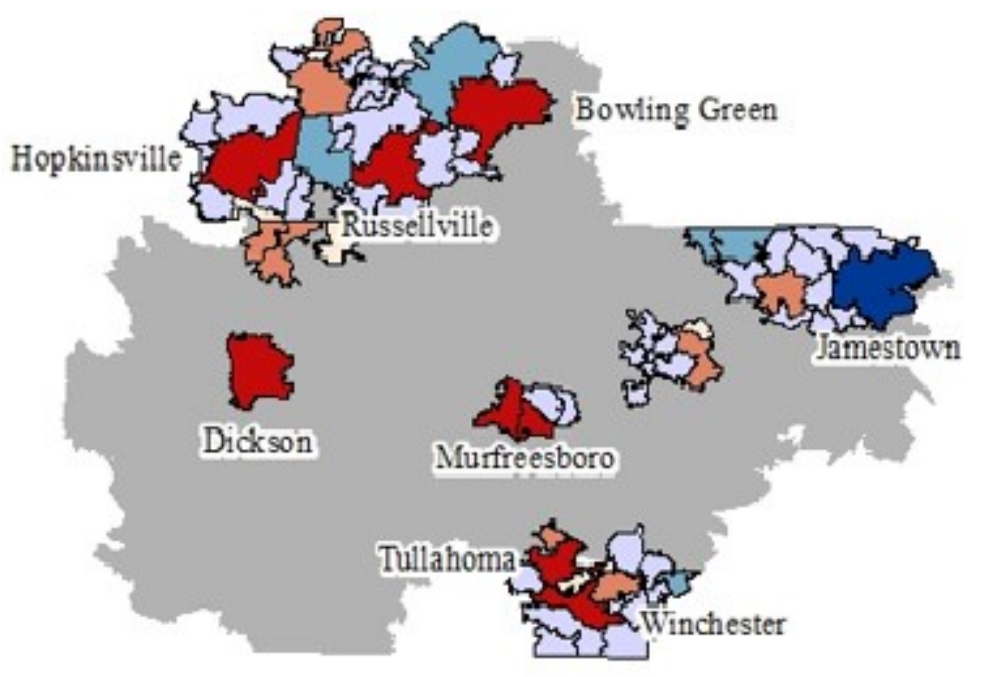

Legend

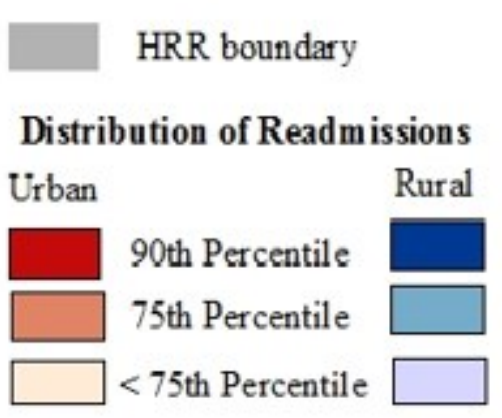

Figure 3-2. Distribution of readmission events across rural and urban ZCTAs within clustered areas of super-utilization in the Nashville HRR.

The distribution of readmissions refers to events attributed to beneficiaries with four or more 30-day readmissions per year. 


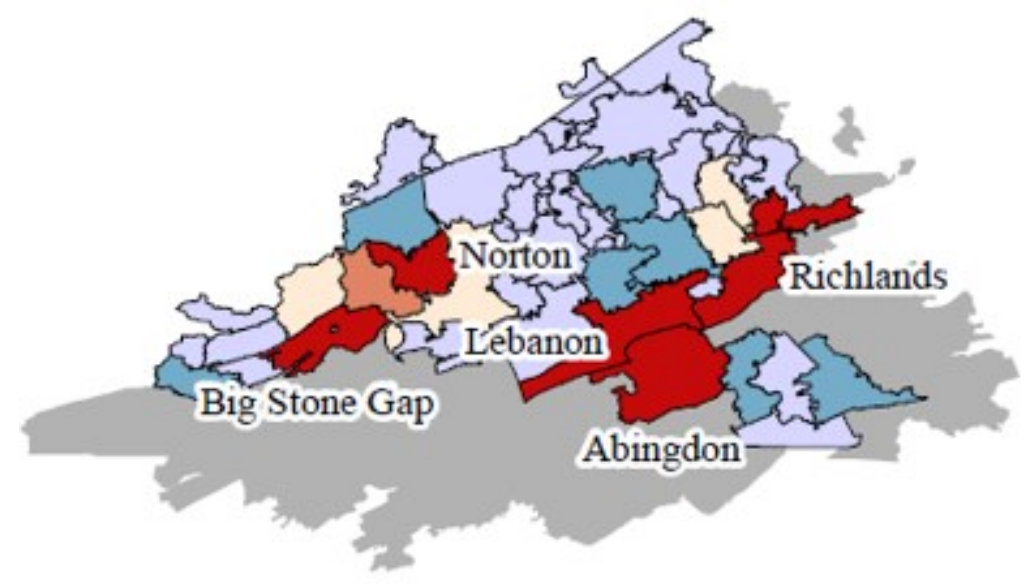

Legend

\begin{tabular}{|c|c|c|}
\hline & HRR boundary & \\
\hline Distri & bution of Readm & ssions \\
\hline Urban & & Rural \\
\hline & 90th Percentile & \\
\hline & 75th Percentile & \\
\hline & $<75$ th Percentile & \\
\hline
\end{tabular}

Figure 3-3. Distribution of readmission events across rural and urban ZCTAs within clustered areas of super-utilization in the Kingsport HRR.

The distribution of readmissions refers to events attributed to beneficiaries with four or more 30-day readmissions per year. 
region. In the Nashville region, six distinct clusters were located throughout the HRR, many separated by considerable land area.

This study also lent clarity to findings in Chapter 2 of high population-based rates of overall readmissions in cross-border areas. Both rurality and challenges to care coordination across state lines were presumed to be factors associated with the high rates in these areas. Findings of this study indicate that rurality is likely not a primary factor associated with high cross-border rates. Although clusters overlapping these cross-border areas in the Nashville and Kingsport HRRs were located in predominantly rural areas, the highest concentration of HRU events within the clusters were located in urban ZCTAs. Tests of statistical significance confirmed that despite fewer urban ZCTAs within clusters in both regions, significantly more readmissions attributed to HRU were located in urban compared to rural ZCTAs. Although non-parametric tests of statistical significant were reported, the level of probability associated with findings demonstrate meaningful results.

Furthermore, the annual number of readmissions attributed to HRU per 100,000 Medicare beneficiaries varied between regions from low values of 312 and 437 in Chattanooga and Knoxville HRRs respectively to high values of 943 in Kingsport and 694 in Jackson HRRs. The same pattern of low and high population-based rates of overall readmissions across HRRs was found in Chapter 2. Hence the current study provides additional evidence that HRU impacts overall rates of readmission.

\section{Implications for Policy and Practice}

Opportunities to address super-utilization exist in all health referral regions across the state. Identification of clusters further informs where to allocate finite resources targeting super-utilization within local healthcare delivery systems, particularly those with high population-based rates of readmission. In addition, cluster locations can also provide information about how to organize the delivery of services provided through programs targeting super-utilizers. For example, clusters in the central and eastern portions of the smaller Jackson HRR are close in proximity while the cluster in the northern, rural portion of the region is separated by a greater distance. While there is potential to distribute shared resources (i.e., outreach workers) across clustered areas in a region, due to proximity of clusters in two different regions, it may also be beneficial to also coordinate efforts between the northern, rural clusters located in the Jackson and Memphis HRRs.

Funding needed to implement interventions such as super-utilizer programs is a critical consideration in addressing HRU. A wide variety of funding mechanisms have been identified that support existing super-utilizer programs (Fisher \& Corrigan, 2014). The number of annual HRU events within a clustered area found in this study may not warrant the level of investment needed to implement super-utilizer programs. However, this study is limited to Medicare beneficiaries ages 65 and older. It is likely that superutilization associated with identified clusters are higher than those reported in this study. For example, the two small, distinct clusters located in the urban core of Memphis are 
likely associated with additional utilization and costs attributed to Medicaid beneficiaries and insured individuals. Based on enrollment in a care transitions program targeting publicly insured super-utilizing patients in the urban core of Memphis, by payer type approximate thirds of individuals enrolled were covered by Medicare only, dually eligible, and Medicaid only (S. Surbhi, personal communication, January 27, 2016). Furthermore, findings from a study of uncompensated (e.g., "charity") hospital care demonstrated super-utilization within the uninsured population in the same zip codes of the Memphis urban core (Barnes et al., 2014). Inclusion of all payer and charity care data in future studies may reveal additional clusters and/or larger boundaries of these urban clusters.

Another consideration in addressing super-utilization is the level of collaboration across multiple providers of health and social services required in order to address the needs of super-utilizing patients. Many local health delivery systems lack the collaborative capacity needed to successfully implement super-utilizer programs. Recent national initiatives such as the Accountable Health Communities program can support development of this important aspect of infrastructure (U.S. Department of Health and Human Services, 2016). This opportunity requires coordination between health and social service providers to address health related social needs of high-risk patient populations. Future national initiatives should consider funding other important aspects of infrastructure development focused on HRU such as access to behavioral healthcare and coordination between providers of mental and physical health services.

In summary, this study demonstrates the capacity to identify areas at high risk for super-utilization using spatial scan statistics. Future studies using similar approaches could be conducted in order to identify at-risk areas within all healthcare delivery systems across the country. Related studies of interest could include adding a temporal component to assess changes in cluster risk over time. In addition, different spatial analysis techniques could be used to investigate the role of health system characteristics, such access to care, in areas with high-risk for super-utilization. 


\section{CHAPTER 4. CAN COMMUNITY DEMOGRAPHIC VARIABLES PREDICT THE RISK OF SUPER-UTILIZATION ACROSS HEALTHCARE DELIVERY SYSTEMS?}

\section{Introduction}

Preventing unnecessary hospital readmissions has become a national priority due to the potential to reduce healthcare expenditures while improving patients' experience of care. Considerable efforts have been made in attempt to predict the risk of hospital readmissions based on patient-level risk factors. According to a comprehensive review of risk prediction models used for both targeting interventions toward high-risk patient populations and comparing hospital quality of care, most of these types of models perform unreliably thus limiting their widespread use (Kansagara et al., 2011). Researchers have begun to take a different perspective on identifying risk for hospital readmissions by focusing on factors related to community demographic variables and health system characteristics. Findings of a recent study that assessed the impact of community factors on hospital readmission rates suggest that these factors may play a more significant role in readmission risk than the quality of hospital care alone (Herrin et al., 2014). Furthermore, it has been demonstrated that the risk of readmission may be highest among socio-economically disadvantaged communities (Kind et al., 2014). This body of research has significant implications for not only how risk of readmission is predicted, but also for what interventional strategies should be undertaken in order to reduce rates of readmission and who should be held accountable for high readmission rates.

This study focuses on the super-utilizing population. Ample evidence exists that this small sub-set of the patient population differs by levels of medical and social complexity from the general patient population (Brenner, 2010). Research that stratifies the readmission distribution by number of readmissions per beneficiary not only highlights disproportionately high utilization and costs associated with this relatively small percentage of patients, but also implicates race and income as factors in high levels of repeat inpatient utilization (Regenstein \& Andres, 2014; Brennan, 2012). This study addresses an existing gap in the literature by focusing on prediction of high repeat utilization (e.g., super-utilization) using community variables. In addition, it relates findings to populations served by health delivery systems. Hence, it has additional implications for prediction of repeat readmission risk, targeting interventions to superutilizing populations, and identifying health delivery systems accountable for disproportionately high inpatient utilization and costs associated with super-utilizers.

The primary aim of this study was to assess the effect of community demographic variables, including income and race, on the presence of high repeat utilization within rural and urban areas. For the purposes of this study, high repeat utilization was defined as readmissions attributed to Medicare beneficiaries with four or more 30-day readmissions in one year. In addition, a secondary aim was to assess whether regional differences in effects of household income by race existed between Tennessee regional 
healthcare delivery systems. A third and final aim was to determine whether effects of household income by race differ by the concentration of low-income households in an area.

\section{Methods}

In this observational study design, Medicare utilization data using 100\% Part A claims for the 2012 calendar year were used. Claims data were linked to geographic boundaries consistent with Dartmouth Atlas of Health Care's definition of hospital referral regions (HRRs) (Wennberg, 1996). In order to do so, readmissions were attributed to the residence of the beneficiary rather than the hospital at which they occurred as described in the Methods section of Chapter 2. The number of beneficiaries and readmission events associated with HRU were aggregated to zip code tabulated areas (ZCTAs) as the primary unit of observation. The study population included all fee-forservice Medicare beneficiaries age 65 and older residing within Tennessee HRRs.

Additional variables linked to ZCTAs included household income data by race for residents ages 65 and older using detailed census tables (United States Census Bureau, 2014). Income categories less than $\$ 20$ thousand per year were combined to represent low-income households. Relationship files from the United States Census Bureau were also used in order to designate ZCTAs as urban and non-urban (e.g., rural) (2010). More specifically, regardless of whether either the entire ZCTA was contained within a larger urbanized area or a portion of the ZCTA was identified as an urban cluster, the ZCTA was designated as urban. All remaining ZCTAs were considered rural.

Data analysis was performed using a logistic regression model as described by Hosmer and Lemeshow (2000). The dependent variable, high repeat utilization, was dichotomized as present or absent within a ZCTA. Independent variables included the number of low-income households by race and rural-urban classification. Region (e.g., HRR) was also included in the model as a class variable. Decomposition analyses were performed using contrasts based on percentiles of the distribution of low-income households in order to determine whether differences in model effects existed at various concentrations of low-income households.

\section{Results}

A total of 1,118 zip codes were included within the Tennessee health referral region (HRR) boundary files. These zip codes were primarily in Tennessee but extended into seven additional states including Alabama, Arkansas, Georgia, Kentucky, Mississippi, North Carolina, and Virginia with hospital service areas (HSAs) within Tennessee HRRs. Nine zip codes located in Missouri and West Virginia were excluded with missing data due to omission from the cross-border claims data request. Fifty eight zip codes representing $4.5 \%$ of the total population were also excluded due to inadvertent omission of full or partial claims data associated with an HSA for which the state of the 
HSA was Tennessee (as opposed to one of the cross-border HSAs); however, the zip code of the city was located in a different state. These data were not recoverable at the time of this study. Additional exclusions of 36 zip codes without Medicare beneficiaries and 14 unique (non-residential) zip codes resulted in a final total of 1,001 zip codes statewide. Zip code data were aggregated to 848 zip code tabulated areas (ZCTAs).

Table 4-1 shows demographic characteristics of the ZCTAs included in this study as well as the presence of HRU by each characteristic. HRU was present in approximately half of all ZCTAs. Despite a greater number of rural ZCTAs, the percent of urban ZCTAs with HRU present (71\%) was much greater compared to the percent of rural ZCTAs with HRU present (32\%). Due to the unequal distribution of HRU throughout urban and rural ZCTAs, effects of low-income households on the presence of HRU were modelled separately in rural and urban areas. Also of importance, relatively few ZCTAs in rural areas contained low-income, black households. Therefore, including both black and white low-income households in the same statistical model would lead to biased standard errors and inferencing of income on HRU in both rural and urban areas. Furthermore, modelling of rural areas did not include low-income, black households. Finally, significant heteroscedasticity in the distribution of low-income households by race prevented comparisons between racial groups within urban areas. The c statistic of the resulting models indicated correct classification of HRU $72 \%$ of the time in the model for low-income, white households in rural areas $(\mathrm{c}=.723), 82 \%$ of the time in the model for low-income, white households in urban areas $(\mathrm{c}=.816)$, and $64 \%$ of the time in the model for low-income, black households in urban areas $(\mathrm{c}=.641)$.

\section{Low-income white households in rural areas}

The mean number of households with annual incomes equal to or less than $\$ 20 \mathrm{~K}$ among whites age 65 and older was 78 across rural ZCTAs (Appendix B). A significant association was found between these low-income households and the presence of HRU within the ZCTA, $\chi 2(1)=45.84, p<.0001$. No significant differences in this association was demonstrated between regions, $\chi 2(6)=1.851, p=.934$. When evaluated at the mean number of households, the odds of having HRU present within the ZCTA was $1 \%$ higher $(\mathrm{OR}=1.01)$. However, results of the decomposition analysis showed significantly higher odds with greater concentrations of low-income households. Ignoring the modelling effect of regional comparisons, the predicted odds of having HRU present within the ZCTA were $16 \%$ higher at the 25 th percentile, $59 \%$ higher at the median, and 2.7 times higher at the 75th percentile. Hence, the most significant increase in odds of HRU was within the most economically disadvantaged neighborhoods in rural areas.

\section{Low-income white households in urban areas}

The mean number of low-income, white households was 342 across urban ZCTAs (Appendix C). Results of the model for low-income, white households found a significant association between low-income households and presence of HRU, $\chi^{2}(1)=$ 
Table 4-1. Characteristics of zip code tabulated areas included in the study.

\begin{tabular}{|lcc}
\hline Characteristics & N (\%) & HRU Present (\%) \\
\hline All ZCTAs & $848(100.0)$ & $421(49.6)$ \\
Urban ZCTAs & $383(45.2)$ & $272(71.0)$ \\
$\begin{array}{l}\text { ZCTAs with low income black } \\
\text { households }\end{array}$ & $212(55.3)$ & $162(76.4)$ \\
$\begin{array}{l}\text { ZCTAs with low income white } \\
\text { households }\end{array}$ & $367(95.8)$ & $269(73.3)$ \\
Rural ZCTAs & $465(54.8)$ & $149(32.0)$ \\
ZCTAs with low income black & $135(29.0)$ & $45(33.3)$ \\
households & $402(86.4)$ & $139(34.6)$ \\
$\begin{array}{l}\text { ZCTAs with low income white } \\
\text { households }\end{array}$ & & \\
Hospital Referral Region & $59(7.0)$ & $29(49.2)$ \\
Chattanooga & $68(8.0)$ & $30(44.1)$ \\
Jackson & $29(3.5)$ & $15(51.7)$ \\
Johnson City & $81(9.5)$ & $43(53.1)$ \\
Kingsport & $144(17.0)$ & $82(56.9)$ \\
Knoxville & $191(22.5)$ & $75(39.3)$ \\
Memphis & $276(32.5)$ & $147(53.3)$ \\
Nashville &
\end{tabular}

Low-income households are defined as those with total annual incomes equal to or less than $\$ 20,000$.

ZCTAs: zip code tabulated areas; HRU: high repeat utilization. 
52.084, $\mathrm{p}<.0001$. Similar to findings of low-income, white households in rural ZCTAs, no regional differences in the association were found, $\chi 2(6)=11.488, \mathrm{p}=.074$. When evaluated at the mean number of households, the odds of having HRU present within the urban ZCTA $0.6 \%$ higher $(\mathrm{OR}=1.006)$. Results of the decomposition analysis in urban ZCTAs also found significantly higher odds with increasing concentrations of white, lowincome households. The predicted odds of having HRU present within the ZCTA were $98 \%$ higher at the 25 th percentile and 5 times higher at the median.

\section{Low-income black households in urban areas}

The mean number of low-income, black households was 78 across urban ZCTAs. Results of the model for urban, low-income, black households also found a significant association between the low-income households and HRU, $\chi 2(1)=5.644, p=.017$. Overall, the odds of HRU being present in urban ZCTAs with the mean number of lowincome, black households was only $0.3 \%$ higher $(\mathrm{OR}=1.003)$. Results of the decomposition analysis on low-income, black households also showed significantly higher odds with increasing concentration of low-income households. The predicted odds of having HRU present within the urban ZCTA were $2.9 \%$ higher at the 50th percentile, $24 \%$ higher at the 75 th percentile, $86 \%$ higher at the 90 th percentile, and 2.9 times higher at the 95 th percentile.

The model for urban, low-income, black households also found significant differences in the presence of HRU between regions, $\chi 2(6)=13.310, p=.038$ (Table 4-2). The predicted odds of having HRU present within an urban ZCTA with lowincome, black households was highest in the Kingsport and Nashville regions, particularly when compared to the Chattanooga and Memphis regions. Compared to Chattanooga, the predicted odds were 2.8 times higher in the Nashville region and 3.9 times higher in the Kingsport region. Compared to the Memphis region, the odds were 2.6 and 3.7 times higher in the Nashville and Kingsport regions respectively.

\section{Discussion}

Findings from this study showed significant effects of low-income households by race, in both rural and urban areas on the presence of high repeat utilization (HRU). While the results did not differ by region for low-income, white households in both rural and urban areas, the odds of HRU being present in urban areas with low-income, black households were significantly higher in Nashville $(\mathrm{OR}=2.78)$ and Kingsport $(\mathrm{OR}=$ 3.93) health referral regions in comparison to Chattanooga. Without consideration of regional variation, the predicted odds of HRU were approximately three times higher across rural and urban areas with the greatest concentration of low-income households regardless of race. Hence, the most economically disadvantaged neighborhoods have the high risk of super-utilization. 
Table 4-2. Odds ratios for regional differences in the presence of high repeat utilization in urban, low-income, black households.

\begin{tabular}{lccccccc}
\hline & \multicolumn{7}{c}{ Reference Region } \\
\cline { 2 - 7 } HRR & Chattanooga & Jackson & Johnson City & Kingsport & Knoxville & Memphis & Nashville \\
\hline Chattanooga & 1.159 & 1.923 & 2.05 & $3.929^{*}$ & 1.745 & 1.063 & $2.783^{*}$ \\
Jackson & 0.520 & 2.229 & 1.066 & 2.043 & 0.907 & 0.553 & 1.447 \\
Johnson City & 0.488 & 0.938 & 2.376 & 1.917 & 0.851 & 0.519 & 1.357 \\
Kingsport & $0.254^{*}$ & 0.489 & 0.522 & $4.555^{*}$ & 0.444 & $0.271^{*}$ & 0.708 \\
Knoxville & 0.573 & 1.102 & 1.175 & 2.252 & $2.023^{*}$ & 0.609 & 1.595 \\
Memphis & 0.940 & 1.809 & 1.928 & $3.695^{*}$ & 1.641 & 1.233 & $2.617^{*}$ \\
Nashville & $0.359^{*}$ & 0.691 & 0.737 & 1.412 & 0.627 & $0.382^{*}$ & $3.225^{*}$ \\
\hline
\end{tabular}

An asterisk denotes statistically significant differences at the .05 probability level. HRR: hospital referral region. 
One surprising finding is the absence of significantly higher odds of HRU being present within urban areas with low-income, black households in the Jackson region given relatively high population-based rates of both overall readmissions and HRU previously reported in Chapters 2 and 3. One possible explanation is the limited performance of logistic regression models at the extreme tails of a distribution or when the distribution of household income within an area is large. In addition, the primary limitation of this study is that predictive models did not account for intra-ZCTA clustering. This may have improved the discriminative ability (e.g., c-statistic) of the model for low-income, black households in urban areas.

These current findings are consistent with prior research demonstrating increased risk of 30-day readmission rates in the most socioeconomically disadvantaged neighborhoods even after adjusting for important patient-level factors such as illness severity (Kind et al, 2014). This research extends these findings specifically to superutilizing populations in socioeconomically disadvantaged areas. It stands to reason that many of the health-related social needs of patients within these areas go largely unmet. However, another important factor to consider is access to high-quality care particularly in the outpatient setting. Indicators of care access and quality may provide greater insight into variation between regions. Future research should include health system characteristics in predictive modelling of high repeat utilization.

Findings from this study provide compelling evidence of high repeat utilization as an indicator of health disparities within the Medicare population. As such, efforts to address HRU could be aligned with the newly established priority areas under The CMS Equity Plan for Improving Quality in Medicare (U.S. Department of Health and Human Services, 2015). For example, identification of areas with disproportionately high utilization and costs associated with repeat readmissions throughout health delivery systems across the country could improve understanding and awareness of disparate outcomes. Furthermore, inclusion of these areas in current CMS programs like the Accountable Health Communities project may be an important part of the solution (U.S. Department of Health and Human Services, 2016). In addition, new opportunities that involve replication of successful super-utilizer programs within integrated delivery systems may also be warranted. Finally, the experience of Quality Improvement Networks and Quality Improvement Organizations (QIN-QIOs) positions them well to play a major role in providing data, engaging community stakeholders, and disseminating evidence-based practices in order to address HRU. 


\section{CHAPTER 5. SUMMARY}

The purpose of this body of research was to identify geographic areas at high risk for high repeat utilization (e.g., super-utilization), or readmission events and inpatient readmission costs attributed to beneficiaries with 4 or more 30-day readmissions per year. Overall findings demonstrated that local healthcare delivery systems with high rates of overall readmissions were more likely to have underlying super-utilization problems. Unsurprisingly, the majority of clusters with concentrated readmissions attributed to super-utilization overlapped local delivery systems with high rates. However, statistically significant clusters were located across all regional healthcare delivery systems including local delivery systems with overall readmission rates no different or lower than the state average. The highest risk of super-utilization occurred in communities with the highest concentration of low-income households, regardless of rural-urban designation, household race, or region. Hence, socio-economically disadvantaged communities likely played a significant role in the variation between and within healthcare delivery systems.

Primary findings from the first essay, The Impact of Super-Utilization on Population-Based Rates of Readmission across Healthcare Delivery Systems, demonstrated significant variation in population-based rates of readmission with an estimated mean of $43(\mathrm{SD}=19)$ readmissions per 1,000 Medicare beneficiaries across local healthcare delivery systems (e.g., hospital service areas). Super-utilizers play an outsized role in hospital service areas (HSAs) in the 90th compared to the 10th percentile of the distribution of readmission rates. In fact, per capita inpatient readmission expenditures were $\$ 173$ across HSAs in the 10th percentile compared to $\$ 616$ across HSAs in the 90th percentile. Finally, readmissions attributed to super-utilizers significantly increased overall readmission rates by an average of 10 readmissions per 1,000 beneficiaries.

Drill down into lower levels of geography within the second essay, Identifying Clusters of Super-Utilization across Healthcare Delivery Systems Using Spatial Scan Statistics, revealed a total of 24 statistically significant clusters of super-utilization across regional healthcare delivery systems (e.g., hospital referral regions). The clusters ranged in size and location from large, predominantly rural clusters to small clusters in urban areas. The relative risk of HRU within clusters ranged from approximately two to seven times the risk in surrounding areas. Furthermore, these clusters overlapped nearly all HSAs with high population-based rates of readmission; however, several clusters also existed in HSAs with rates no different or lower than the state average. Finally, within large, predominantly rural clusters that crossed state lines, readmission events were actually concentrated in fewer, small urban areas rather than dispersed over the rural areas.

Findings from the third and final essay, Can Community Demographic Variables Predict the Risk of Super-Utilization across Healthcare Delivery Systems, demonstrated higher odds of super-utilization in both rural and urban areas with low-income white and 
black households. No regional differences in effects were noted among low-income white households in either rural or urban areas. However, the effects of low-income black households on the presence of super-utilization in urban areas were greater in some regions than others. Perhaps of greatest importance, a differential effect of increasing concentrations of low-income households on super-utilization existed across rural and urban areas among both races. In fact, the predicted odds of HRU were approximately three times higher in areas with the greatest concentration of low-income households. Hence, the risk of super-utilization was greatest in economically disadvantaged communities.

The financial burden of super-utilization is enormous. Across all Tennessee HRRs, Medicare spent $\$ 308$ million on inpatient readmission expenditures for beneficiaries ages 65 and older in 2012 alone. Approximately $\$ 43$ million (14\%) was spent on $1 \%$ of all beneficiaries with 4 or more 30-day readmissions and a total of $\$ 83$ million $(27 \%)$ on $2 \%$ of all beneficiaries with 3 or more 30 -day readmissions. In addition, nearly half or approximately $\$ 19$ million, of the cost of HRU occurred within a handful of local healthcare delivery systems in the 90th percentile of the distribution of overall readmission rates. However, these numbers represent only a portion of the annual cost attributed to super-utilizers as they do not account for expenditures related to emergency department use, medication fills, or ambulatory care. Furthermore, it does not include any expenditures attributed to dually eligible beneficiaries less than 65 years old, Medicaid-only beneficiaries, uninsured patients, or commercially insured patients. The final price tag on HRU could be staggering to say the least.

However, the social burden of super-utilization is equally disheartening. Throughout this research, the geographic areas at increased risk for super-utilization correspond with where people live within the healthcare delivery systems that serve them. There is increasing acknowledgement that where people live influences their health and well-being whether via poor access to either resources in the environment needed for self-management of complex chronic conditions or high-value, patientcentered care (Goodman, et al., 2012; Robert Wood Johnson Foundation, 2011). Essay three in particular, highlights super-utilization as a likely indicator of health disparities. Based on years of working with super-utilizing patients within the context of health and healthcare improvement, there is little that is super about the quality of life associated with excessive hospitalizations, challenges to self-management, or the experience of fragmented and often inadequate care within this patient population.

The stakes involved in super-utilization extend well beyond the patient population. The future viability of the Medicare program depends on being able to bend the healthcare cost curve. State budgets are strained by Medicaid expenditures as well, leaving less-than-desirable appropriations for education, public safety, or parks and recreation. Consumers with commercial insurance are not immune to the ripple effect of cost-shifting between payers on premiums. Improving care for the small percentage of super-utilizing patients may provide an opportunity to exponentially decrease the rate of readmissions and their associated costs to payers and ultimately, consumers. From a provider perspective, financial stability can be uncertain in an era of declining 
reimbursements and new risk-sharing payment models. The super-utilizing population adversely influences already- shrinking health care margins. However, providers that develop the capacity to deliver care that is responsive to the needs of super-utilizing populations will be well positioned to thrive under the new models of payment. With regard to patients, super-utilizers are not the only patient population that will likely benefit from improvements to system-level processes of care needed to adequately address HRU. For example, improved care coordination between providers, increased access to mental health services, and greater resources for chronic disease selfmanagement and risk reduction can improve the experience of care for a much broader range of patients. Finally, beyond stakeholders in the healthcare arena, improving the health status of residents in disadvantaged communities and decreasing time lost to inefficient medical care is beneficial to both existing and potential employers resulting in more employment opportunities and greater economic livelihood. Improving health and productivity of residents also allows their greater contribution to community through activities like providing informal care for children, disabled adults, and elderly family members and friends; participating in neighborhood safety, restoration, or gardening projects; and being active in social support networks through churches, senior centers, and other places of local interest.

The findings of this research can be used to inform population health initiatives focused on super-utilization within regional healthcare delivery systems (e.g., HRRs). Geographic variation in readmission rates and patterns of HRU clusters demonstrated in these studies suggest that intervention strategies need to be implemented in response to the challenges of local healthcare delivery systems (e.g., HSAs). Although all local delivery systems can benefit from continued implementation of readmission reduction initiatives, not all will require the same level of investment in super-utilizer programs. Hence, findings can be used specifically to efficiently and equitably allocate finite resources and organize delivery of program services to areas with high potential for reduced per capita readmission costs, improved population-based rates of readmission, and improved experience of care for super-utilizing patients.

Although this research provides regional intelligence needed to achieve the Triple Aim applied to super-utilization in geographic regions, several primary challenges exist (Institute for Healthcare Improvement, 2011). First, successfully addressing superutilization will also require integration of delivery systems in order to coordinate care across multiple providers and settings including behavioral health and community-based services that can address common health-related social needs. Second, creative solutions to payment for innovative care practices are needed until payment reform mechanisms like population-based global payment and re-investment of ACO shared savings reach critical mass. Regions can look to multiple funding sources for implementation of new super-utilizing programs including membership fees in regional health improvement collaboratives, community benefit funds of non-profit hospitals, health and wellness trusts funded through local and state taxes, social investing, and community development financing (Fisher \& Corrigan, 2014). Third, there must be an entity to engage all relevant stakeholders in a common purpose as well as foster shared learning and monitor progress at a minimum (Institute of Healthcare Improvement, 2011). Due to experience in 
engaging communities in readmission reduction initiatives, spreading evidence-based practices, and evaluating impact, Medicare Quality Improvement Organizations are wellpositioned to play a significant role in supporting regional efforts to address superutilization.

The study population and area included in this research are Medicare beneficiaries ages 65 and older across Tennessee healthcare delivery systems. It is likely that high-risk areas identified are not confined to the study population for several reasons. First evidence exists that concentrations of super-utilizing patients beyond the study population are located within some of the same clustered areas (Barnes et al., 2014). Furthermore, it stands to reason that if socioeconomically disadvantaged communities play a significant role in the location of super-utilizers, then the composition of these communities likely include publicly insured and uninsured patients. Nevertheless, overall findings should be interpreted with caution as they may not be generalizable to other populations or areas. However, the importance of these studies does extend beyond the study population and area. As demonstration studies, the unique methodological approaches can be scaled to both healthcare delivery systems across the country and additional payers.

The findings of this study also have implications for national policy and investments that can support efforts to address super-utilization. One example would be to use population-based rates of readmission similar to those reported in this research to assess penalties among local healthcare delivery systems with excessive rates through the Hospital Readmission Reduction Program. This alternative has the potential to impact delivery systems who are outliers with the highest rates of population-based readmissions and therefore, those faced with super-utilizer challenges. As mentioned previously, nearly half of all Medicare inpatient readmission expenditures attributed to HRU occurred within the top ten percent of local healthcare delivery systems with the highest population-based readmission rates.

Incorporating population health initiatives to address super-utilization into National Partnership for Patients strategies has potential to achieve an accelerated decrease in the national rate of readmissions and therefore, significant cost savings to the Medicare program. However, the majority of national readmission reduction initiatives to date have not included super-utilizer types of programs (Mathematica, 2014; Econometrica, 2013; Ventura et al., 2010). Inclusion of super-utilizer interventions in future programs similar to the Community-based Care Transitions Program could improve the return on national investments. Similarly, inclusion of super-utilizer interventions in State Innovation Models Initiative could expand cost-savings to the Medicaid program as well. In addition, programs like the Accountability Health Communities initiative are needed in order to develop infrastructure to address medical and social complexity of super-utilizing populations across healthcare delivery systems. Future national initiatives should consider funding other important aspects of infrastructure development focused on HRU such as access to behavioral healthcare and coordination between providers of mental and physical health services. Replication of studies similar to the current research can inform preference selection of communities for 
state and national investments to target super-utilization. However, future studies should strive to include multiple sources of data from additional payer and provider entities. Furthermore, these data can also play a role in monitoring inclusion of disadvantaged communities in implementation of delivery reform activities.

There are two important areas of future research that can further inform efforts to address super-utilization. First, this study included only community demographic variables in predictive modeling of areas at increased risk of HRU. However, there are likely health system characteristics also associated with increased risk of HRU across areas. For example, access to behavioral health services and quality of primary care may be important factors to consider. Future research should work toward more comprehensive models of risk prediction geared toward populations served by local healthcare delivery systems.

Second, although existing literature informs characteristics often associated with super-utilizing populations, there are gaps in the literature about how these patients currently experience care. Understanding the current experience of care is essential to improving care and ensuring that it is patient-centered. This type of inquiry is even more important for super-utilizing populations in order to align quality improvement strategies with the lifestyle, cultural preferences, and social dynamics that influence selfmanagement behaviors among vulnerable populations.

In summary, super-utilization is not only a costly problem but also a significant indicator of health disparities. Accountability for super-utilization must be expanded throughout a healthcare delivery system. Engagement of all stakeholders in efforts to reduce super-utilization will be necessary to successfully address the issue. Continued learning based on previous readmission reduction efforts as well as shared learning for new strategies that offer potential to achieve accelerated reductions in readmission rates and increases in cost savings is needed. Findings from ongoing and expanded studies that identify where super-utilization occurs can be used to inform where and how to allocate finite healthcare resources in order to address these disproportionately high patterns of utilization and costs. Efforts must be taken to ensure that allocation of healthcare resources are equitable across populations served by these delivery systems. New and strengthened policies focusing on super-utilization are needed to support organization of service delivery and transformation of healthcare delivery systems. This research is a significant step toward addressing the issue of super-utilization. Continued research is needed to further inform the issue through improved prediction, intervention, and monitoring of these efforts. 


\section{LIST OF REFERENCES}

Anderson, G. F. \& Steinberg, E. P. (1984). Hospital readmissions in the Medicare population. The New England Journal of Medicine, 311, 1349-1353. doi:10.1056/NEJM198411223112105

ArcMap (Version 10.2) [GIS computer software]. Redlands, CA: EsriC).

Barnes, P., Cutts, T., Dickinson, S., Guo, H., Squires, D., Bowman, S., \& Gunderson, G. (2014). Methods for managing and analyzing electronic medical records: a formative examination of a hospital-congregation-based intervention. Population Health Management, 17(5), 279-286. doi: 10.1089/pop.2013.0078

Bernheim, S. M., Grady, J. N., Lin, Z., Wang, Y., Wang. Y., Savage, S. V., ... Krumholz, H. M. (2010). National patterns of risk-standardized mortality and readmission for acute myocardial infarction and heart failure, update on publicly reported outcome measures based on the 2010 release. Circulation: Cardiovascular Quality and Outcomes, 3, 459-467. doi:10.1161/CIRCOUTCOMES.110.957613

Berwick, D. M., Nolan, T. W., \& Whittington, J. (2008). The triple aim: care, health, and cost. Health Affairs, 27(3), 759-769. doi:10.1377/hlthaff.27.3.759

Boccuti, C. \& Casillas, G. (2015, January). Aiming for fewer u-turns: the Medicare hospital readmission reduction program (Issue Brief). Retrieved from The Henry J. Kaiser Family Foundation website: http://kff.org/medicare/issue-brief/aiming-forfewer-hospital-u-turns-the-medicare-hospital-readmission-reduction-program/

Boutwell, A., Griffin, F., Hwu, S., \& Shannon, D. (2009). Effective interventions to reduce rehospitalizations: a compendium of 15 promising interventions. Retrieved from Institute for Healthcare Improvement website:

http://www.ihi.org/resources/Pages/Changes/EffectiveInterventionstoReduceRehospitalizationsCompendium15PromisingInterventions.aspx

Brennan, N. (2012, June). National Medicare readmission findings: recent data and trends. Presentation at the Annual Research Meeting of AcademyHealth, Orlando

FL. Retrieved from http://www.academyhealth.org/files/2012/sunday/brennan.pdf

Brenner, J. (2010). Building an accountable care organization in Camden, NJ. Prescriptions for Excellence in Health Care, 1(9). Retrieved from http://jdc.jefferson.edu/pehc/vol1/iss9/5

Brock, J., Mitchell, J., Irby, K., Stevens, B., Archibald, T., Goroski, A., \& Lynn, J. (2013). Association between quality improvement for care transitions in communities and rehospitalizations among Medicare beneficiaries. The Journal of the American Medical Association, 309(4), 381-391. doi:10.1001/jama.2012.216607

Center for Healthcare Strategies, Inc. (2015). Programs focusing on high-need, high-cost populations. Retrieved from http://www.chcs.org/resource/programs-focusing-highneed-high-cost-populations/

The Center for Medicare \& Medicaid Services (2014a). New HHS data shows major strides in patient safety, leading to improved care and savings. Retrieved from https://innovation.cms.gov/Files/reports/patient-safety-results.pdf

The Center for Medicare \& Medicaid Services (2014b). Welcome to the partnership for patients. Retrieved from https://partnershipforpatients.cms.gov/ 
Chronic Condition Data Warehouse (2012). Medicare beneficiaries eligible for Medicaid. Retrieved from http://www.healthindicators.gov/Indicators/Medicarebeneficiaries-eligible-for-Medicaid-percent 317/

Cohen, S. B. (2014). The concentration and persistence in the level of health expenditures over time: estimates for the U.S. population, 2011-2012 (Statistical Brief No. 449). Retrieved from Agency for Healthcare Research and Quality website: http://meps.ahrq.gov/mepsweb/data files/publications/st449/stat449.pdf

Cromley, E. K. \& McLafferty, S. L. (2002). GIS and public health. New York: The Guilford Press.

The Dartmouth Atlas of Health Care (2010). Post-acute care, percent of patients readmitted within 30 days of discharge, by cohort. Retrieved from http://www.dartmouthatlas.org/data/topic/topic.aspx?cat=30

The Dartmouth Atlas of Health Care (2012). ZIP code crosswalks. [Geographic crosswalk and boundary data files]. Retrieved from http://www.dartmouthatlas.org/downloads/geography/ZipHsaHrr12.xls

Econometrica, Inc. (2014). Evaluation of the community-based care transitions program (Contract No. HHSM-500-2011-00015I). Retrieved from https://innovation.cms.gov/Files/reports/CCTP-AnnualRpt1.pdf

Felitti, V. J., Anda, R. F., Nordenberg, D., Williamson, D. F., Spitz, A. M., Edwards, V., . .. Marks, J. S. (1998). Relationship of childhood abuse and household dysfunction to many of the leading causes of death in adults The adverse childhood experiences (ACE) study. American Journal of Preventive Medicine, 14(4), 245-258. doi:10.1016/S0749-3797(98)00017-8

Fisher, E. S. \& Corrigan, J. (2014). Accountable health communities, getting there from here. The Journal of the American Medical Association, 312(20), 2093-2094. doi:10.1001/jama.2014.13815

Gawande, A. (2011, January 24). The hot spotters. The New Yorker, pp. 41, 51.

Gerhardt, G., Yemane, A., Hickman, P., Oelschlaeger, A., Rollins, E., \& Brennan, N. (2013). Data shows reduction in Medicare hospital readmission rates during 2012. Medicare \& Medicaid Research Review, 3(2). doi:10.5600/mmrr.003.02.b.01

Goodman, D. C., Brownlee, S., Chang, C. H. \& Fisher, E. S. (2010). Regional variation in primary care and the quality of care among Medicare beneficiaries. Retrieved from the Dartmouth Atlas of Health Care Website: http://www.dartmouthatlas.org/downloads/reports/Primary care report 090910.pdf

Goodman, D. C., Fisher, E. S., \& Chang, C. H. (2011). After hospitalization: a Dartmouth atlas report on post-acute care for Medicare beneficiaries. Retrieved from the Dartmouth Atlas of Health Care Website: http://www.dartmouthatlas.org/downloads/reports/Post_discharge events 092811.pdf

Hasselman, D. (2013). Super-utilizer summit Common themes from innovative complex care management programs. Retrieved from the Robert Wood Johnson Foundation website: http://www.rwjf.org/content/dam/farm/reports/reports/2013/rwjf407990

Health Affairs (2013, November). Medicare hospital readmission reduction program (Health Policy Brief 102). Retrieved from http://www.healthaffairs.org/healthpolicybriefs/brief.php?Brief_id=102 
Hempstead, K., DeLia, D., Cantor, J. C., Nguyen, T. \& Brenner, J. (2014). The fragmentation of hospital use among a cohort of high utilizers: implications for emerging care coordination strategies for patients with multiple chronic conditions. Medical Care, 52(3), 67-74. doi:10.1097/ MLR.0000000000000049

Herrin, J., St. Andre, J., Kenward, K., Joshi, M. S., Audet, A. J., \& Hines, S. C. (2014). Community factors and hospital readmission rates. Health Services Research 50(1), 20-36. doi:10.1111/1475-6773.12177

Hosmer, D. W. \& Lemeshow, S. (2000). Applied Logistic Regression, 2nd edition. New York: John Wiley \& Sons, Inc.

Institute for Healthcare Improvement (2011, March). Achieving the triple aim in geographic regions: looking ahead. Retrieved from http://www.ihi.org/Engage/Initiatives/TripleAim/Pages/default.aspx

Jencks, S. F. (2010, December). Fixing hospital readmissions: growing momentum. Webinar presentation of the Chartered Value Exchange through the Agency for Healthcare Research and Quality.

Jenck, S. F. (2014, December 16). Protecting hospitals that improve population health [Web log post]. Retrieved from http://medicaring.org/2014/12/16/protectinghospitals/

Jencks, S. F., Williams, M. V., \& Coleman, E. A. (2009). Rehospitalizations among patients in the Medicare fee-for-service program. New England Journal of Medicine, 360, 1418-1428. doi:10.1056/ NEJMsa0803563

John Snow, Inc. (2012). ZIP code to ZCTA crosswalk. [Crosswalk data file]. Retrieved from http://www.udsmapper.org/zcta-crosswalk.cfm

Kansagara, D., Englander, H., Salanitro, A., Kagen, D., Theobald, C., Freeman, M., \& Kripalani, S. (2011). Risk prediction models for hospital readmission: a systematic review. The Journal of the American Medical Association, 306(15), 1688-1698. doi:10.1001/jama.2011.1515

Kind, A. J., Jencks, S., Brock, J., Yu, M. Bartels, C., Ehlenbach, W., ... Smith, M. (2014). Neighborhood socioeconomic disadvantage and 30-day rehospitalization: a retrospective cohort study. Annals of Internal Medicine, 161(11), 765-774. doi: 10.7326/M13-2946

Kronick, R. G., Bella, M., \& Gilmer, T. P. (2009). The faces of Medicaid III: refining the portrait of people with multiple chronic conditions. Retrieved from Center for Health Care Strategies website: http://www.chcs.org/media/Faces of Medicaid III.pdf

Kulldorff, M. (1997). A spatial scan statistic. Communications in Statistics: Theory and Methods, 26, 1481-1496. doi:10.1080/03610929708831995

Malone, R.E. (1995). Heavy users of emergency services: social construction of a policy problem. Social Science \& Medicine, 40(4), 469-477. doi:10.1016/02779536(94)E0116-A

Mathematica (2014). Project evaluation activity in support of partnership for patients: task 2 evaluation progress report (Contract No. GS-10F-0166R). Retrieved from https://innovation.cms.gov/Files/reports/PFPEvalProgRpt.pdf

Moy, E., Chang, E., \& Barret, M. (2013). Potentially preventable hospitalizations United States, 2001-2009. Morbidity and Mortality Weekly Report, 62(3), 139-143. 
Regenstein, M., \& Andres, E. (2014). Reducing hospital readmissions among Medicaid patients: a review of the literature. Quality Management in Health Care, 23(4), 203225. doi:10.1097/ QMH0000000000000043

Robert Wood Johnson Foundation (2011, September). How does where we live, work, learn and play affect our health? (Issue Brief). Retrieved from http://www.rwjf.org/content/dam/farm/reports/issue briefs/2011/rwjf71339

Robert Wood Johnson Foundation (2012, October). Robert Wood Johnson Foundation awards \$2.1 million in grants to improve care, reduce costs for most expensive patients. Retrieved from http://www.rwjf.org/en/library/articles-andnews/2012/10/rwjf-funds-program-to-improve-care-for-super-utilizers.html

Sandberg, S. F., Erikson, C., Owen, R., Vickery, K. D., Shimotsu, S. T., Linzer, M., . . . DeCubellis, J. (2014). Hennepin health: a safety-net accountable care organization for the expanded Medicaid population. Health Affairs, 33(11), 1975-1984. doi:10.1377/hlthaff.2014.0648

SatScan ${ }^{\mathrm{TM}}$ (Version 9.4) [Computer software]. Boston, MA: Kulldorf \& Information Management Service Incorporated.

Sugarman, J.R. (May, 2015). Community care transitions in the $11^{\text {th }}$ scope of work: Qualis Health's approach and early results. [Presentation on QIO monthly call]

United States Census Bureau (2010a). ZIP Code ${ }^{\mathrm{TM}}$ Tabulation Areas ZCTAs $^{\mathrm{TM}}$ ). Retrieved from https://www.census.gov/geo/reference/zctas.html

United States Census Bureau (2010b). TIGER/Line ${ }^{\circledR}$ shapefiles and TIGER/Line ${ }^{\circledR}$ files. [Shapefiles]. Retrieved from https://www.census.gov/geo/maps-data/data/tiger$\underline{\text { line.html }}$

United States Census Bureau (2010c). 2010 census urban and rural classification and urban area criteria [Relationship data files]. Retrieved from https://www.census.gov/geo/reference/ua/urban-rural-2010.html

United States Census Bureau (2014d). 2010-2014 American community survey 5-year estimates, age of householder by household income past 12 months [Detailed data tables B19037A \& B19037B]. Retrieved from http://factfinder.census.gov

United States Department of Health and Human Services, Centers for Medicare \& Medicaid Services, Office of Minority Health (2015). The CMS equity plan for improving quality in Medicare. Retrieved from https://www.cms.gov/AboutCMS/Agency-Information/OMH/OMH_Dwnld-

CMS EquityPlanforMedicare 090615.pdf

United States Department of Health and Human Services, Centers for Medicare \& Medicaid Services (2016). Affordable Care Act funding opportunity: accountable health communities. [Funding opportunity announcement]. Retrieved from https://innovation.cms.gov/initiatives/ahcm

Ventura, T., Brown, D., Archibald, T., Goroski, A., \& Brock, J. (2010). Improving care transitions and reducing hospital readmissions: establishing the evidence for community-based implementation strategies through the care transitions theme. Retrieved from the Remington Report website: http://remingtonreport.com

Wennberg, J. E. (1996). Appendix on the geography of health care in the United States. In M. Cooper (Ed.), The Dartmouth Atlas of Health Care in the United States (pp. 289-307). Retrieved from http://www.dartmouthatlas.org/downloads/methods/geogappdx.pdf 


\section{APPENDIX A. COMPARISONS OF COMMUNITY-BASED RATES OF READMISSION TO THE STATEWIDE PER CAPITA READMISSIONS ACROSS TENNESSEE HOSPITAL SERVICE AREAS}

\begin{tabular}{|c|c|c|c|c|c|c|c|c|c|}
\hline HRR & HSA & $\begin{array}{c}\mathbf{n} \\
\text { ZCTAs } \\
\end{array}$ & CBRR & SD & SE & LLCI & ULCI & $\mathbf{Z}$ & p \\
\hline \multirow{8}{*}{ 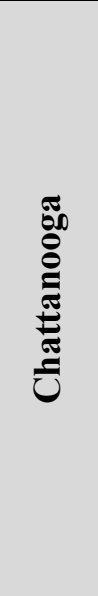 } & $\begin{array}{l}\text { Bridgeport } \\
\text { Fort }\end{array}$ & 2 & 30.11 & 12.49 & 8.83 & 0.00 & 142.31 & -1.26 & 0.206 \\
\hline & Oglethorpe & 5 & 39.00 & 10.74 & 4.80 & 25.67 & 52.33 & $\begin{array}{c}0.46 \\
-\end{array}$ & 0.642 \\
\hline & Chattanooga & 29 & 30.83 & 11.07 & 2.06 & 26.62 & 35.04 & 18.77 & $<.001$ \\
\hline & Cleveland & 11 & 29.64 & 9.12 & 2.75 & 23.51 & 35.76 & 10.09 & $<.001$ \\
\hline & Copperhill & 4 & 7.91 & 5.76 & 2.88 & 0.00 & 17.08 & 20.89 & $<.001$ \\
\hline & Dayton & 2 & 14.49 & 5.17 & 3.65 & 0.00 & 60.90 & -9.10 & $<.001$ \\
\hline & $\begin{array}{l}\text { Pikeville } \\
\text { South }\end{array}$ & 1 & 13.81 & & & & & & \\
\hline & Pittsburg & 3 & 41.31 & 5.27 & 3.04 & 28.23 & 54.40 & 1.89 & 0.059 \\
\hline \multirow{8}{*}{ 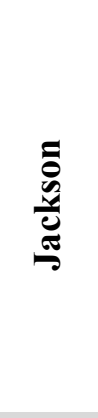 } & Huntingdon & 9 & 36.45 & 15.80 & 5.27 & 24.30 & 48.59 & -.89 & 0.376 \\
\hline & Jackson & 33 & 50.81 & 20.45 & 3.56 & 43.56 & 58.06 & 20.68 & $<.001$ \\
\hline & Lexington & 3 & 67.93 & 17.79 & 10.27 & 23.73 & 112.12 & 5.05 & $<.001$ \\
\hline & Martin & 6 & 51.30 & 21.69 & 8.86 & 28.54 & 74.06 & 3.68 & $<.001$ \\
\hline & McKenzie & 2 & 64.45 & 7.75 & 5.48 & 0.00 & 134.05 & 6.83 & $<.001$ \\
\hline & Milan & 1 & 57.66 & & & & & & \\
\hline & Paris & 7 & 30.43 & 10.50 & 3.97 & 20.72 & 40.13 & -5.05 & $<.001$ \\
\hline & Parsons & 6 & 54.48 & 21.54 & 8.79 & 31.88 & 77.08 & 4.59 & $<.001$ \\
\hline \multirow{4}{*}{ 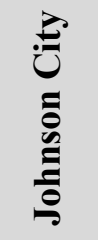 } & Banner Elk & 2 & 11.33 & 1.78 & 1.26 & 0.00 & 27.35 & 29.92 & $<.001$ \\
\hline & Boone & 9 & 39.29 & 19.77 & 6.59 & 24.09 & 54.49 & 0.59 & 0.557 \\
\hline & Erwin & 2 & 50.29 & 4.83 & 3.41 & 6.91 & 93.66 & 5.09 & $<.001$ \\
\hline & Johnson City & 14 & 36.66 & 11.83 & 3.16 & 29.83 & 43.49 & -1.59 & 0.112 \\
\hline \multirow{11}{*}{ 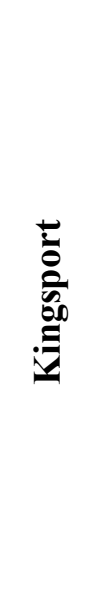 } & Jenkins & 1 & 5.50 & & & & & & \\
\hline & Bristol & 3 & 36.21 & 5.08 & 2.93 & 23.59 & 48.82 & -1.06 & 0.290 \\
\hline & Kingsport & 11 & 21.56 & 7.58 & 2.28 & 16.47 & 26.65 & -23.86 & $<.001$ \\
\hline & Abingdon & 7 & 52.79 & 11.81 & 4.46 & 41.86 & 63.71 & 8.76 & $<.001$ \\
\hline & Big Stone Gap & 4 & 104.60 & 74.04 & 37.02 & 0.00 & 222.41 & 3.60 & $<.001$ \\
\hline & Clintwood & 4 & 69.10 & 16.82 & 8.41 & 42.34 & 95.87 & 7.40 & $<.001$ \\
\hline & Grundy & 8 & 48.67 & 34.06 & 12.04 & 20.20 & 77.15 & 2.51 & 0.012 \\
\hline & Lebanon & 9 & 72.59 & 38.37 & 12.79 & 43.09 & 102.08 & 8.11 & $<.001$ \\
\hline & Marion & 6 & 43.33 & 19.34 & 7.90 & 23.03 & 63.62 & 1.65 & 0.099 \\
\hline & $\begin{array}{l}\text { Norton } \\
\text { Pennington }\end{array}$ & 5 & 69.96 & 16.73 & 7.48 & 49.20 & 90.73 & 9.56 & $<.001$ \\
\hline & Gap & 5 & 57.75 & 19.20 & 8.59 & 33.90 & 81.59 & 5.14 & $<.001$ \\
\hline
\end{tabular}




\begin{tabular}{|c|c|c|c|c|c|c|c|c|c|}
\hline & Richlands & 11 & 81.23 & 39.82 & 12.01 & 54.48 & 107.98 & 11.94 & $<.001$ \\
\hline \multirow{20}{*}{ 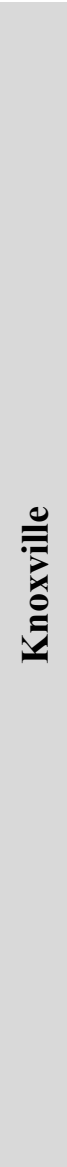 } & Middlesboro & 2 & 59.87 & 35.46 & 25.07 & 0.00 & 378.43 & 1.23 & 0.217 \\
\hline & Pineville & 10 & 105.94 & 73.43 & 23.22 & 53.41 & 158.47 & 9.25 & $<.001$ \\
\hline & Athens & 4 & 25.32 & 11.59 & 5.79 & 6.89 & 43.76 & -4.38 & $<.001$ \\
\hline & Etowah & 4 & 24.27 & 16.78 & 8.39 & 0.00 & 50.97 & -3.27 & 0.001 \\
\hline & Greeneville & 8 & 32.66 & 10.41 & 3.68 & 23.95 & 41.36 & -4.11 & $<.001$ \\
\hline & Harriman & 2 & 35.52 & 10.00 & 7.07 & 0.00 & 125.33 & -0.50 & 0.620 \\
\hline & Jefferson City & 2 & 32.60 & 3.96 & 2.80 & 0.00 & 68.21 & -2.72 & 0.006 \\
\hline & Jellico & 3 & 66.50 & 36.27 & 20.94 & 0.00 & 156.61 & 2.36 & 0.018 \\
\hline & Knoxville & 38 & 25.93 & 13.15 & 2.13 & 21.61 & 30.25 & 34.88 & $<.001$ \\
\hline & La Follette & 5 & 44.42 & 29.74 & 13.30 & 7.49 & 81.34 & 1.08 & 0.281 \\
\hline & Maryville & 11 & 26.39 & 10.56 & 3.18 & 19.30 & 33.48 & 12.10 & $<.001$ \\
\hline & Morristown & 9 & 39.52 & 10.16 & 3.39 & 31.71 & 47.33 & 1.35 & 0.178 \\
\hline & Newport & 6 & 40.99 & 18.61 & 7.60 & 21.46 & 60.51 & 0.96 & 0.335 \\
\hline & Oak Ridge & 11 & 31.89 & 18.58 & 5.60 & 19.40 & 44.37 & -3.62 & $<.001$ \\
\hline & Oneida & 6 & 21.34 & 11.37 & 4.64 & 9.41 & 33.27 & -8.79 & $<.001$ \\
\hline & Rockwood & 2 & 25.59 & 21.19 & 14.99 & 0.00 & 216.00 & -1.17 & 0.242 \\
\hline & Rogersville & 1 & 25.80 & & & & & & \\
\hline & Sevierville & 4 & 23.60 & 6.30 & 3.15 & 13.57 & 33.63 & -9.14 & $<.001$ \\
\hline & Sweetwater & 4 & 36.48 & 12.35 & 6.18 & 16.83 & 56.14 & -.49 & 0.623 \\
\hline & Tazewell & 6 & 40.10 & 14.51 & 5.92 & 24.87 & 55.33 & 0.87 & 0.385 \\
\hline \multirow{18}{*}{ 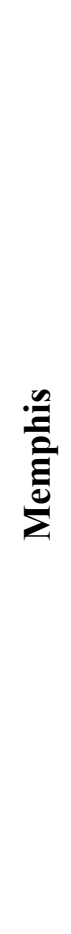 } & Blytheville & 1 & 53.44 & & & & & & \\
\hline & Forrest City & 7 & 29.27 & 16.59 & 6.27 & 13.92 & 44.61 & -3.69 & $<.001$ \\
\hline & Helena & 6 & 36.58 & 16.22 & 6.62 & 19.56 & 53.59 & -0.53 & 0.598 \\
\hline & Osceola* & 6 & 22.24 & 27.16 & 11.09 & 0.00 & 50.74 & -3.48 & $<.001$ \\
\hline & West Memphis & 11 & 36.34 & 19.10 & 5.76 & 23.50 & 49.17 & -0.96 & 0.339 \\
\hline & Wynne* & 3 & 5.45 & 6.91 & 3.99 & 0.00 & 22.60 & -14.14 & $<.001$ \\
\hline & Clarksdale & 12 & 66.57 & 50.64 & 14.62 & 34.40 & 98.75 & 6.77 & $<.001$ \\
\hline & Cleveland & 9 & 97.18 & 77.03 & 25.68 & 37.97 & 156.40 & 6.91 & $<.001$ \\
\hline & Corinth & 6 & 42.24 & 11.43 & 4.67 & 30.24 & 54.24 & 2.22 & 0.026 \\
\hline & Greenville & 10 & 45.86 & 23.23 & 7.35 & 29.24 & 62.48 & 3.38 & 0.001 \\
\hline & Marks & 1 & 21.57 & & & & & & \\
\hline & Ripley & 5 & 45.91 & 12.87 & 5.75 & 29.93 & 61.89 & 3.07 & 0.002 \\
\hline & Brownsville & 2 & 34.47 & 11.96 & 8.46 & 0.00 & 141.94 & -.59 & 0.555 \\
\hline & Covington & 2 & 40.22 & 4.11 & 2.91 & 3.29 & 77.15 & 1.08 & 0.280 \\
\hline & Dyersburg & 4 & 76.46 & 31.94 & 15.97 & 25.63 & 127.28 & 4.82 & $<.001$ \\
\hline & Memphis & 52 & 37.43 & 15.42 & 2.14 & 33.14 & 41.72 & -1.92 & 0.055 \\
\hline & Ripley & 3 & 35.14 & 4.84 & 2.79 & 23.12 & 47.16 & -1.77 & 0.076 \\
\hline & Savannah & 7 & 25.81 & 21.54 & 8.14 & 5.88 & 45.73 & -3.96 & $<.001$ \\
\hline
\end{tabular}




\begin{tabular}{|c|c|c|c|c|c|c|c|c|c|}
\hline & Selmer & 4 & 26.65 & 22.55 & 11.27 & 0.00 & 62.53 & -2.01 & 0.044 \\
\hline & Union City & 8 & 39.50 & 16.56 & 5.86 & 25.65 & 53.35 & 0.73 & 0.468 \\
\hline \multirow{36}{*}{$\begin{array}{l}\stackrel{0}{\bar{z}} \\
\frac{1}{5} \\
z \\
z\end{array}$} & $\begin{array}{l}\text { Bowling } \\
\text { Green }\end{array}$ & 19 & 44.90 & 22.27 & 5.11 & 34.17 & 55.64 & 5.89 & $<.001$ \\
\hline & Franklin & 1 & 29.90 & & & & & & \\
\hline & Greenville & 10 & 38.08 & 24.62 & 7.79 & 20.47 & 55.69 & 0.03 & 0.973 \\
\hline & Hopkinsville & 9 & 50.61 & 29.75 & 9.92 & 27.74 & 73.48 & 3.81 & $<.001$ \\
\hline & Russellville & 6 & 55.93 & 23.16 & 9.45 & 31.63 & 80.23 & 4.65 & $<.001$ \\
\hline & Camden* & 3 & 22.22 & 22.81 & 13.17 & 0.00 & 78.88 & -2.08 & 0.038 \\
\hline & Carthage & 8 & 46.54 & 12.65 & 4.47 & 35.96 & 57.12 & 5.40 & $<.001$ \\
\hline & Celina & 2 & 90.79 & 27.24 & 19.26 & 0.00 & 335.54 & 3.88 & $<.001$ \\
\hline & Centerville & 2 & 25.43 & 1.91 & 1.35 & 8.23 & 42.63 & 13.13 & $<.001$ \\
\hline & Clarksville & 10 & 43.72 & 17.89 & 5.66 & 30.92 & 56.52 & 3.20 & 0.001 \\
\hline & Columbia & 10 & 43.18 & 12.09 & 3.82 & 34.54 & 51.83 & 4.29 & $<.001$ \\
\hline & Cookeville & 5 & 59.16 & 17.01 & 7.61 & 38.04 & 80.28 & 6.22 & $<.001$ \\
\hline & Crossville & 10 & 41.67 & 24.78 & 7.84 & 23.94 & 59.40 & 1.48 & 0.139 \\
\hline & Dickson & 10 & 39.47 & 16.82 & 5.32 & 27.43 & 51.50 & 0.87 & 0.383 \\
\hline & Erin & 4 & 18.74 & 6.85 & 3.42 & 7.84 & 29.63 & -11.25 & $<.001$ \\
\hline & Franklin & 8 & 24.71 & 14.40 & 5.09 & 12.67 & 36.75 & -7.38 & $<.001$ \\
\hline & Gainesboro & 3 & 37.36 & 19.03 & 10.99 & 0.00 & 84.64 & -0.10 & 0.919 \\
\hline & Gallatin & 4 & 40.28 & 5.62 & 2.81 & 31.34 & 49.21 & 1.62 & 0.105 \\
\hline & Hartsville & 2 & 11.39 & 4.42 & 3.12 & 0.00 & 51.06 & 12.05 & $<.001$ \\
\hline & Hendersonville & 1 & 29.36 & & & & & & \\
\hline & Jamestown & 3 & 66.74 & 32.60 & 18.82 & 0.00 & 147.74 & 2.64 & 0.008 \\
\hline & Lafayette & 2 & 46.32 & 14.73 & 10.42 & 0.00 & 178.67 & 1.13 & 0.259 \\
\hline & Lawrenceburg & 6 & 50.29 & 5.56 & 2.27 & 44.46 & 56.12 & 13.27 & $<.001$ \\
\hline & Lebanon & 4 & 28.36 & 6.69 & 3.34 & 17.72 & 39.00 & -5.77 & $<.001$ \\
\hline & Lewisburg & 4 & 28.58 & 4.05 & 2.03 & 22.13 & 35.03 & -9.30 & $<.001$ \\
\hline & Linden & 3 & 48.31 & 22.39 & 12.93 & 0.00 & 103.92 & 1.38 & 0.167 \\
\hline & Livingston & 9 & 57.35 & 21.86 & 7.29 & 40.54 & 74.15 & 7.97 & $<.001$ \\
\hline & Madison & 5 & 28.48 & 4.47 & 2.00 & 22.93 & 34.04 & 10.64 & $<.001$ \\
\hline & Manchester & 4 & 51.20 & 16.37 & 8.18 & 25.16 & 77.25 & 3.23 & 0.001 \\
\hline & McMinnville & 6 & 45.99 & 9.49 & 3.88 & 36.03 & 55.95 & 5.05 & $<.001$ \\
\hline & Murfreesboro & 11 & 41.80 & 10.88 & 3.28 & 34.49 & 49.11 & 3.85 & $<.001$ \\
\hline & Nashville & 32 & 31.66 & 8.67 & 1.53 & 28.53 & 34.78 & 23.40 & $<.001$ \\
\hline & Portland & 1 & 34.14 & & & & & & \\
\hline & Pulaski & 4 & 33.83 & 7.13 & 3.57 & 22.49 & 45.18 & -2.34 & 0.019 \\
\hline & Shelbyville & 3 & 31.72 & 14.88 & 8.59 & 0.00 & 68.69 & -1.27 & 0.205 \\
\hline & Smithville & 3 & 43.93 & 11.32 & 6.54 & 15.81 & 72.05 & 1.57 & 0.116 \\
\hline
\end{tabular}




\begin{tabular}{lcccccccc|} 
Sparta & 4 & 34.97 & 10.43 & 5.22 & 18.37 & 51.57 & -1.16 & 0.246 \\
Springfield & 6 & 32.20 & 10.64 & 4.34 & 21.04 & 43.36 & -3.27 & 0.001 \\
Tullahoma & 3 & 69.33 & 10.76 & 6.21 & 42.60 & 96.06 & 8.74 & $<.001$ \\
Waverly & 3 & 31.76 & 13.74 & 7.93 & 0.00 & 65.89 & -1.36 & 0.173 \\
Waynesboro & 2 & 51.93 & 42.99 & 30.40 & 0.00 & 438.14 & 0.65 & 0.517 \\
Winchester & 12 & 65.29 & 26.99 & 7.79 & 48.14 & 82.44 & 12.13 & $<.001$ \\
Woodbury & 3 & 45.08 & 22.02 & 12.71 & 0.00 & 99.77 & 0.97 & 0.334 \\
& & & & & & & & \\
Ashland City & 2 & 23.78 & 13.82 & 9.77 & 0.00 & 147.95 & -2.06 & 0.040 \\
\hline
\end{tabular}

HRR: hospital referral region; HSA: hospital service area; ZCTA: zip code tabulated area; CBRR: community-based readmission rate; LLCI: lower limit confidence interval; ULCI: upper limit confidence interval.

Asterisk after HSA names indicates over dispersion of the distribution and lowered confidence in the estimated CBRR. 


\section{APPENDIX B. DISTRIBUTION OF LOW-INCOME, WHITE HOUSEHOLDS ACROSS RURAL ZCTAS}

\begin{tabular}{lc}
\hline Characteristics & House holds \\
\hline Mean & 78 \\
Std. deviation & 91 \\
Skewness & 2 \\
Kurtosis & 4 \\
IQR & 89 \\
Minimum & 0 \\
25th percentile & 16 \\
Median & 48 \\
75th percentile & 105 \\
95th percentile & 285 \\
Maximum & 529 \\
\hline
\end{tabular}

Data based on 465 rural zip code tabulated areas (ZCTAs).

Low-income is defined as total annual household income equal to or below $\$ 20,000$. 


\section{APPENDIX C. DISTRIBUTION OF LOW-INCOME HOUSEHOLDS BY RACE ACROSS URBAN ZIP CODE TABULATED AREAS}

\begin{tabular}{lcc}
\hline & \multicolumn{2}{c}{ Race } \\
\cline { 2 - 3 } Characteristics & Black & White \\
\hline Mean & 73 & 342 \\
Std. deviation & 167 & 311 \\
Skewness & 5 & 1 \\
Kurtosis & 38 & 2 \\
IQR & 74 & 374 \\
Minimum & 0 & 0 \\
25th percentile & 0 & 108 \\
Median & 10 & 255 \\
75th percentile & 74 & 482 \\
95th percentile & 374 & 1001 \\
Maximum & 1733 & 1678 \\
\hline
\end{tabular}

Data based on 383 urban zip code tabulated areas (ZCTAs).

Low-income is defined as total annual household income equal to or below $\$ 20,000$. 


\section{VITA}

Jill Nault was born in 1970 to Harlen and Einona Heikkila and grew up in a rural area of Michigan's Upper Peninsula, a special community with a rich history in iron mining and the lumber industry. It was there that she learned the most important lessons in life, the values of a hard work ethic, perseverance, and faith. Jill went on to complete bachelor and master degrees that provided an educational background in health and chronic disease prevention. In 1999, she entered the world of academia, working as a lifestyle coach in the NIH-funded National Diabetes Prevention Program, a randomized controlled trial designed to test the effects of lifestyle change and medication on the prevention of Type 2 diabetes in an impaired glucose tolerant population. As a result of working with program participants in the urban core of Memphis, Tennessee, Jill discovered her true passion for learning about psychosocial aspects of living with chronic disease and the effects of social determinants on health. In 2005, she completed an additional master's degree in social work with a macro concentration focusing on social service delivery at the systems level. After five years of experience working in program evaluation in the field of health and human services, Jill returned to the academic setting to work full-time while entering a PhD program in Health Outcomes \& Policy Research. With the passage of the Affordable Care Act in 2010, she was thrust into the world of health reform. For the next five years Jill studied the legislation from a scholarly perspective while working on multiple national health reform initiatives including Robert Wood Johnson Foundation's Aligning Forces for Quality, Medicare Quality Improvement Organizations' 10th Scope of Work for Care Transitions, and a Health Care Innovation Award (HCIA) through the Centers for Medicare \& Medicaid Innovation. During the HCIA initiative, she had the privilege to work with patients in the 'superutilizing' population, an experiential learning opportunity focused on patient experience of care. Upon completion of this dissertation and graduation from the University of Tennessee Health Science Center in May of 2016, Jill will continue to pursue her research interests in health disparities and behavioral health through an AcademyHealth post-doctoral fellowship in the Geisinger Health System. 